\title{
Life-Cycle Asset Allocation with Ambiguity Aversion and Learning*
}

\author{
Kim Peijnenburg $^{\dagger}$ \\ Bocconi University
}

November 18, 2011

\begin{abstract}
I show that ambiguity (Knightian uncertainty) and learning about the equity premium can explain the fraction of financial wealth allocated to stocks over the life cycle and the stock market participation puzzle. I assume that individuals are ambiguous about the equity premium and are averse with respect to this ambiguity, which results in a lower optimal allocation to stocks over the life cycle. As agents get older, they learn about the equity premium and increase their allocation to stocks. Cohort effects can be identified via learning, since each cohort has different stock market experiences and thus differ in their beliefs. Time effects are identified via decreasing fees over time. Two ways to include ambiguity aversion in the model are examined: recursive smooth preferences and maximin utility preferences. I find that if agents have maximin preferences, the empirically observed allocation to stocks can be matched. However, the stylized facts cannot be replicated when agents have smooth recursive preferences with only moderate risk aversion.
\end{abstract}

Keywords: Life-cycle portfolio choice, ambiguity aversion, learning, behavioral finance JEL classification: D14, D8, D91, G11

${ }^{*}$ I thank Johannes Binswanger, Katie Carman, Meltem Daysal, Joost Driessen, Rob van de Goorbergh, Thijs van der Heijden, Philipp Illeditsch, Frank de Jong, Ralph Koijen, Marieke Knoef, Bertrand Melenberg, Olivia Mitchell, Roderick Molenaar, Theo Nijman, Paolo Porchia, Lisanne Sanders, Arthur van Soest, Peter Snoeren, Kent Smetters, Stefan Trautmann, Raman Uppal, Bas Werker, and seminar participants at BI Norwegian School of Management, Bocconi, Catolica Lisbon, Erasmus University, IE Business School, Stockholm School of Economics, Tilburg University, University of Geneva, VU University Amsterdam, TIBER conference, and the Tilburg Center of Finance conference for helpful comments and suggestions. Part of this research was conducted while I was visiting the Wharton School of the University of Pennsylvania, and I am grateful for their hospitality. I acknowledge financial support by All Pensions Group (APG). The most recent version of this paper is available at www.kimpeijnenburg.com.

${ }^{\dagger}$ Finance department, Bocconi University, IGIER, and Netspar, Milan, 20136, Italy. Phone: 390258362723. Email: kim.peijnenburg@unibocconi.it. 


\section{Introduction}

The key inputs of a life-cycle model, such as the equity risk premium, variance of stock returns, and labor income risk, are generally assumed to be known by the agent. Optimal portfolio allocations, consumption, and savings are calculated as if the agent takes these parameters as given, and the resulting optimal policies are subsequently compared to the empirically observed life-cycle patterns. However, the predictions of most life-cycle models do not match well with some of the empirical findings. For instance, the shape of participation in the stock market over the life cycle and, more generally, the overall low participation rates are ill understood. Furthermore, the humpshaped allocation to stocks, conditional on participation in the stock market, appears difficult to align with the predictions from life-cycle models. I propose a standard life-cycle model, taking into account that agents are ambiguous about the equity risk premium and are averse to this ambiguity (in contrast to the ambiguity neutral approach). During their lifetime individuals learn about the equity premium. With this parsimonious adjustment to the standard framework I can explain both the life-cycle pattern of participation in the stock market and the conditional allocation to equity. Furthermore, with this structural model I can separately identify, age, cohort, and time effects in the allocation to stocks over the life cycle.

In this paper I assume that agents not only face risk, but are uncertain about the true parameters describing this risk (Knight (1921)). ${ }^{1}$ A common way to deal with parameter uncertainty is the ambiguity-neutral approach, where the decision maker treats the unknown parameters as random variables and combines his prior belief about the parameter with observed signals, which forms the predictive distribution. He evaluates his expected utility with respect to this predictive distribution. In this case the agent is ambiguous but is not ambiguity averse. However, there is substantial evidence that agents are not neutral with respect to this parameter uncertainty (see for instance the classical work on the Ellsberg paradox which demonstrates ambiguity aversion with an urn experiment, Ellsberg (1961)). In this paper agents are not ambiguity neutral, but are ambiguity averse. I assume ambiguity about the equity risk premium, but I do not assume a certain origin for this ambiguity. Ambiguity about the equity premium can arise from, for instance, a lack of statistical evidence, a lack of theoretical evidence, unsophistication of investors, and so on. Focussing on statistical ambiguity, even when every agent possesses all the historical stock return data over the past 100 years and uses these to estimate the equity premium, the confidence interval will still be sizeable: for example $[4 \%-2 * 20 \% / \sqrt{100}: 4 \%+2 * 20 \% / \sqrt{100}]=[+0 \%:+8 \%]$. A short note on terminology is in order. As Guidolin and Rinaldi (2010) point out, in the literature am-

\footnotetext{
${ }^{1}$ The difference between risk and uncertainty is that when agents face risk they can attach probabilities to random events, while when facing uncertainty they do not know the probabilities. In the context of this paper, the agent faces risk because the return on stocks is stochastic, but the agent is also uncertain because he does not know the expected stock return.
} 
biguity and uncertainty are not always distinguished, nor clearly defined. Throughout the paper I use the terms uncertainty and ambiguity interchangeably, and I define ambiguity/uncertainty as a random event where the probabilities are not given (as opposed to a coin toss), but agents have a distribution of priors over the uncertain parameter. ${ }^{2}$

I explore two preference models to include ambiguity aversion; (1) maximin preferences and (2) smooth recursive preferences. Gilboa and Schmeidler (1989) propose that agents have maximin preferences in a multiple priors framework, which entails that agents evaluate policies by maximizing utility according to the worst case belief. This atemporal framework is generalized by Epstein and Schneider (2003) to a dynamic setup. Klibanoff, Marinacci, and Mukerji (2005) introduce a smooth ambiguity model, which allows a separation between ambiguity (the level of uncertainty) and ambiguity aversion (taste with respect to ambiguity). I present the two models of ambiguity as being separate, but, as shown in Klibanoff, Marinacci, and Mukerji (2005), the maximin preference model is a limiting case of the smooth recursive preferences when the degree of ambiguity tends to infinity. There is no consensus in the literature on whether agents behave according to smooth recursive preference (with moderate ambiguity aversion) or maximin preferences (i.e., there is no consensus on the degree of ambiguity aversion) and, as I will show, both have widely varying implications for optimal portfolio allocation, with minimax better matching the data. I do not assume that agents learn about the equity risk premium in a rational manner; agents weigh realizations of stock return during life with a prior belief about the equity risk premium, putting no weight on returns before age 20. Malmendier and Nagel (2010) find that agents' "experienced return" has a larger influence on beliefs about the equity risk premium than stock return realizations before birth. I assume agents learn independently of stock market participation and I employ Bayes' rule as the updating rule for the beliefs about the equity risk premium.

In their seminal works, Merton (1969) and Samuelson (1969) find that agents should hold a constant fraction in risky assets over the life cycle in the absence of labor income and complete markets. More recent work by Benzoni, Collin-Dufresne, and Goldstein (2007), Cocco, Gomes, and Maenhout (2005), Heaton and Lucas (2000), Polkovnichenko (2007), and Viceira (2001) examines the effect of (risky) labor income on the optimal portfolio choice. If human capital is riskless, young agents have a substantial investment in this "bond-like" asset and, as a result, invest a large fraction of their liquid wealth in risky assets. This is in contrast to the empirically observed low allocation to stocks, especially early in the life cycle. Others, such as Cocco (2005) and Yao and Zhang (2005), include housing in a dynamic framework and examine the portfolio choice implications. However, the empirical life-cycle patterns of low stock market participation

\footnotetext{
${ }^{2}$ In this paper, I assume a set of priors about the equity risk premium, and I restrict the set to be normally distributed. As I will show later, when using smooth recursive ambiguity preferences, it is necessary to have a probability measure over the set of priors. When using maximin preferences it is not necessary to attach probabilities to the set of priors.
} 
and low equity holdings are hard to match with these models.

The contributions of this paper are threefold. First, I find that ambiguity with respect to equity premium can have a substantial effect on the optimal stock allocation. This paper is the first, to my knowledge, that examines the impact of ambiguity aversion and learning on optimal portfolio allocation in a life-cycle model, comparing both maximin preferences and smooth recursive preferences. When modeled via smooth recursive preferences with moderate ambiguity aversion, I find that the influence of ambiguity aversion and learning is small. In contrast, if agents have maximin preferences and are thus more ambiguity averse, ambiguity aversion does have a sizeable impact on optimal portfolio choices. The stock market participation decreases substantially as well as the conditional allocation to equity. Both effects decrease with age due to learning about the equity premium, since learning results in young agents being more ambiguous about the equity premium compared to older agents.

Second, this structural model with ambiguity aversion and learning allows identification of age, cohort, and time effects. In a reduced form model age patterns of stock allocation cannot be identified separately, from cohort effects and time effects, since time, age, and cohort do not vary independently. ${ }^{3}$ There are several rationales for why agents should optimally change their allocation to risky assets with age; for instance human capital, which is examined in Benzoni, Collin-Dufresne, and Goldstein (2007) and Cocco, Gomes, and Maenhout (2005). Furthermore ambiguity aversion and learning about the expected stock return induces age effects, which is the focus of this paper. Cohort effects relate to individuals' experiences during life, common to those growing up at the same time, which may influence behavior and beliefs. For instance high stock returns can lead to upward revisions in expectations about future stock returns (see Malmendier and Nagel (2010)). Cohort effects in the model are generated due to learning about the expected stock return. This results in differences between cohorts in their optimal allocation to stocks; for instance a 25-year old in 2007 has a different mean belief about the equity premium compared to a 25 -year old in 1989 due to a difference in the realized stock returns in the preceding years. Time effects can arise for a variety of reasons, for instance due to decreasing fees or lower costs of obtaining information over time. In the model, time effects are generated due to a decrease in transaction fees over time.

Third, when I compare the optimal fraction allocated to stocks to the empirical levels, I find a very close match when assuming that cohort effects are zero, and a lesser match when cohort effects are added. If cohort effects are excluded, the predicted fraction to stocks deviates not more than 25\% from the empirical levels at all ages, in the examined years 2007, 1998, and 1989. A comparable good match is found when examining the participation in the stock market. Hence by

\footnotetext{
${ }^{3}$ The identification problem arises because age equals time minus cohort (birth year). Ameriks and Zeldes (2004) and Poterba and Samwick (1997) try to uncover specific age patterns, but reach inconclusive results.
} 
extending the often used life-cycle model calibrated by Cocco, Gomes, and Maenhout (2005) with ambiguity aversion and learning, I can explain the observed stock allocations.

In contrast to other papers, I do not need to include several additional features in the model to be able to explain low stock allocations, such as participation costs (Paiella (2001) and VissingJorgenson (2002)), Epstein-Zin preferences, bequests, housing, cointegration between labor income and dividends, and so forth, and the intuitive modification with ambiguity aversion can explain the empirical evidence very closely. Similar to this paper, Gomes and Michaelides (2005) try to match the empirically observed allocation to stocks by assuming a bequest motive, fixed entry costs of $2.5 \%$ of income, preference heterogeneity, and Epstein-Zin preferences. The participation levels match closely, except after retirement, however the predictions about the conditional allocation to equity differ about $40 \%$ from the empirically observed levels at younger ages. I can match the allocation to equity conditional on participation in the stock market very well, especially at young ages. Benzoni, Collin-Dufresne, and Goldstein (2007) assume cointegration between stock and labor markets and find a hump-shaped allocation to equity, however the absolute differences with empirical levels are substantially larger than the findings in this paper.

Two other papers include ambiguity and learning about the parameters in a life-cycle framework and address similar questions as in this paper. Campanale (2009) assumes agents have maximin preferences, are uncertain about the probability of a high stock return, and face fixed stock market participation costs. The return on stocks can take on two values, high or low. Learning occurs when agents invest in the stock market, and only with a percentage lower than $100 \%$ if they do not participate. Hence participation in the stock market is encouraged, since it generates information about the expected stock returns. The learning process differs from this paper, where both non-participants and participants receive the same information about the stock market. Campanale (2009) finds that ambiguity aversion about the expected stock return can rationalize lower stock market participation. Linnainmaa (2007) examines the influence of ambiguity in a life-cycle framework, but maximizes over financial wealth and stock prices follow a binomial tree. In contrast to both papers I identify age, cohort, and time effects, which are then compared to the data. Hence I do not make the identifying assumption that cohort and time effects are zero. Campanale (2009) points out the potential of a life-cycle model with ambiguity aversion and learning to calculate cohort effects, but leaves this for further research.

Two closely related strands of literature look at the implications of ambiguity on (1) portfolio choice, and (2) asset pricing, from a non life-cycle perspective. Cao, Wang, and Zhang (2005) find that model uncertainty can help explain the limited participation, and Dow, Ribeiro, and Werlang (1992) come to similar conclusions. Related to both papers, Easley and O'Hara (2009) model ambiguity about expected stock returns and show how regulation of the market moderates the effect of ambiguity. The influence of ambiguity on portfolio holdings are furthermore examined 
in for instance Bossaerts, Ghirardato, Guarnaschelli, and Zame (2010), and Garlappi, Uppal, and Wang (2007). ${ }^{4}$ This paper differs in two important aspects. Namely, I examine ambiguity aversion and learning in the context of a life-cycle model, so I not only explain the mean of stock market participation and conditional allocation to equity aggregated over all ages, but at all ages. In addition, I compare the implications of the two most employed ways to incorporate ambiguity aversion, smooth recursive preferences and maximin preferences. The second strand of literature examines the asset pricing implications of ambiguity and learning and explore whether this can explain the equity premium puzzle (Ju and Miao (2010) and Leippold, Trojani, and Vanini (2008)). ${ }^{5}$

The remainder of the paper is organized as follows. Section 2 describes the life-cycle model, in which I include ambiguity aversion and learning. In Section 3 I show the impact of ambiguity about the equity risk premium on optimal portfolio choices and compares the results from the life-cycle model with the empirical evidence. Section 4 presents the results for smooth recursive preferences. Robustness tests are subsequently performed in Section 5. Section 6 concludes.

\section{The model}

I extend the standard life-cycle framework by including ambiguity aversion and learning. Two often used ways to do this are (1) maximin preferences and (2) smooth recursive preferences. ${ }^{6}$ Essentially, the smooth recursive framework with infinite ambiguity aversion equals the maximin preferences framework. However, in the literature they are often presented as a separate framework instead of the maximin preferences being a special case of the smooth preferences model. In

\footnotetext{
${ }^{4}$ Other papers relating stock allocations and ambiguity are Epstein and Schneider (2008), Illeditsch (2010), and Williams (2009) who look at ambiguous information. Illeditsch (2010) shows that ambiguous information can give rise to portfolio inertia. Faria, Correira-Da-Silva, and Ribeiro (2009) model ambiguity about the volatility of stock returns, while Gagliardini, Porchia, and Trojani (2009) model ambiguity averse agents and examine the implications for the term structure of interest rates. Easley and O'Hara (2010) find that illiquidity arises due to uncertainty, and at certain prices there are no trades. Furthermore, Cvitanic, Lazrak, Martellini, and Zapatero (2006) conclude that uncertain agents have an incentive to trade induced by learning about the expected return on stocks. Related to this Mele and Sangiorgi (2009) examine costly information acquisition to reduce uncertainty. Furthermore, a "flight to familiar assets" can arise if agents are less uncertain about some assets compared to others, which is explored in Boyle, Garlappi, Uppal, and Wang (2009). Other papers relating portfolio choice and ambiguity are Miao (2009) and Liu (2010).

${ }^{5}$ Similarly, Hayashi and Wada (2010) examine the asset pricing implications using a recursive smooth ambiguity preferences model. Buraschi and Jiltsov (2006) determine the option pricing implications for agents who face model uncertainty, while Chen and Epstein (2002) model ambiguity in a continuous time setting and explore the influence on the equity premium. The references in this paragraph are far from comprehensive, since the ambiguity literature is large and growing fast and hence cannot be summarized in one section. Some excellent and recent reviews on this literature are Epstein and Schneider (2010) and Guidolin and Rinaldi (2010).

${ }^{6}$ An alternative way to include uncertainty stems from the robust control literature (Hansen and Sargent (2001)). The idea is that the decision rules also work well (are robust) if there is some model misspecification. Related to this paper, Maenhout (2004) explores the impact of uncertainty on asset prices and portfolio allocation in a robust control framework.
} 
compliance with the literature, I explore the implications of ambiguity aversion and learning on equity allocation via both frameworks, because there is considerable debate on whether agents exhibit smooth preferences or kinked preferences (maximin preferences). ${ }^{7}$

\subsection{The individuals preferences}

I consider a life-cycle investor of age $t=1, \ldots, T$, where $t$ is the adult age, $T$ is the maximum age possible, and $K$ is the retirement age. Individuals maximize utility over consumption and preferences are represented by a time-separable utility function over consumption $\left(C_{t}\right)$. The agent's decision variables at time $t$ are consumption $C_{t}$ and stock weight $w_{t}$.

\subsubsection{Maximin preferences}

For comparison, in the standard life-cycle model without ambiguity, the individuals preferences are defined as

$$
V_{t}=\max _{w_{t}, C_{t}} u\left(C_{t}\right)+\beta p_{t+1} \mathbb{E}_{t}\left\{V_{t+1}\left(W_{t+1}\right)\right\}
$$

where $\beta$ is the time preference discount factor, $u$ is the utility function, and $C_{t}$ is the amount of wealth consumed at the beginning of period $t$. The optimal fraction allocated to stocks is denoted by $w_{t}$, which is implicit in $W_{t+1}$. The probability of surviving to age $t+1$, conditional on having lived to period $t$, is indicated by $p_{t+1}$.

I assume investors preferences are described by maximin expected utility, which essentially means that agents maximize expected utility according to the belief which generates the lowest utility. Gilboa and Schmeidler (1989) axiomatize this behavior in a static setting and Epstein and Schneider (2003) in a dynamic framework. I assume that the agent is uncertain about the equity premium and updates his beliefs according to realized stock market returns, which can be either actively or passively observed. The updates of the beliefs about the equity risk premium follow from Bayes' rule, which is described in Section 2.5. The mean belief about the equity risk premium is denoted by $\lambda_{t}^{B}$ and the standard deviation by $\sigma_{t}^{B} . \lambda_{t}^{B}$ and $\sigma_{t}^{B}$ describe the set of priors, which are normally distributed. The domain of equity premiums that the agents thinks possible at time $t, \Lambda_{t}$, is given by $\left[\lambda_{t}^{B}-2 \sigma_{t}^{B}, \lambda_{t}^{B}+2 \sigma_{t}^{B}\right]$. Garlappi, Uppal, and Wang (2007) make a related assumption when incorporating ambiguity by stating that the expected return of an asset lies within a specified

\footnotetext{
${ }^{7}$ Ahn, Choi, Gale, and Kariv (2010) explicitly compare via a portfolio choice experiment the maximin preferences and smooth preferences to explore which describes actual behavior best and find evidence in favor of a kinked specification (maximin preferences). Other papers that examine (the amount of) uncertainty or effects of uncertainty on portfolio choice via experiments are Abdellaoui, Baillon, Placido, and Wakker (2010), Bossaerts, Ghirardato, Guarnaschelli, and Zame (2010), and Hayashi and Wada (2010).
} 
confidence interval of its estimated value, and the agent behaves as if the worst case belief in the confidence interval is the true belief. Hence the mean of the belief about the equity premium, $\lambda_{t}^{B}$, is not the only possible value of the equity premium. But the true mean is expected to lie within a 95\% confidence interval of beliefs about the equity premium.

As described above, the agent is uncertain about the equity premium and tries to maximize the value function at each period $t$,

$$
\begin{aligned}
V_{t} & =\max _{w_{t}, C_{t} \lambda \in \Lambda_{t}}\left[u\left(C_{t}\right)+\beta p_{t+1} \mathbb{E}_{t}^{\lambda}\left\{V_{t+1}\left(W_{t+1}\right)\right\}\right], \text { with } \\
u\left(C_{t}\right) & =\frac{C_{t}^{1-\gamma}}{1-\gamma},
\end{aligned}
$$

where $E_{t}^{\lambda}$ is the expectation calculated as if $\lambda$ is the true equity premium. I assume a CRRA utility function, $u$, and $\gamma$ is the risk aversion coefficient. In effect, the agent maximizes expected utility as if $\lambda_{t}^{B}-2 \sigma_{t}^{B}$ is the equity premium. Note that I assume that the agent limits his beliefs to a range of possible equity premium, a confidence interval. An interval of beliefs instead of the entire distribution is not only intuitive but also necessary, because the beliefs are normally distributed and hence the worst belief is infinitely negative. Furthermore, for the maximin preferences to be a limiting case of the recursive smooth preferences the worst case prior must be the same in both frameworks.

\subsubsection{Recursive smooth preferences}

In addition to examining the effect of ambiguity about the equity risk premium and learning on the allocation to risky assets via maximin preferences, I also employ smooth preferences. I assume preferences as specified in Klibanoff, Marinacci, and Mukerji (2005), which include an ambiguity function $\phi$ and total optimal lifetime utility equals

$$
\begin{aligned}
V_{t} & =\max _{w_{t}, C_{t}} u\left(C_{t}\right)+\beta p_{t+1} \phi^{-1}\left(\int_{\Lambda_{t}} \phi\left(\mathbb{E}_{t}^{\lambda}\left\{V_{t+1}\left(W_{t+1}\right)\right\}\right) p_{t}(\lambda) d \lambda\right), \\
u\left(C_{t}\right) & =\frac{C_{t}^{1-\gamma}}{1-\gamma} \\
\phi(x) & =-\exp (-\alpha x),
\end{aligned}
$$

where $\phi$ is the constant relative ambiguity aversion function (CRAA) and $\alpha$ is the ambiguity aversion coefficient. This power-exponential specification is employed in Collard, Mukerji, Sheppard, and Tallon (2009), Klibanoff, Marinacci, and Mukerji (2009), and Klibanoff, Marinacci, and Mukerji (2005). Think of each prior $\lambda_{t} \in \Lambda_{t}$ as describing a possible scenario (a possible equity risk 
premium) and $p_{t}(\lambda)$ as the probabilistic belief over the different scenarios. This utility function can be interpreted as being solved in two stages. First, the expected utility for all the priors in $\Lambda_{t}$ are calculated, to get a set of expected utilities. Maximin would then take the minimum of these expected utilities, while smooth preferences takes an expectation over the distorted probabilities. The ambiguity aversion function $\phi$ distorts the probabilities, giving a higher weight to lower expected utilities, reflecting ambiguity aversion. Recursive smooth preferences allow a separation between ambiguity, i.e., the subjective beliefs of the individuals, and ambiguity aversion, which reflects the decisions makers' tastes with respect to the ambiguity. This separation between ambiguity and ambiguity aversion is not possible with maximin preferences.

\subsection{The individuals constraints}

The individual faces a number of constraints on the consumption and investment decisions. First, I assume that the agent faces borrowing and short-sales constraints

$$
w_{t} \geq 0 \text { and } \iota^{\prime} w_{t} \leq 1
$$

Second, I impose that the investor is liquidity constrained

$$
C_{t} \leq W_{t}+Y_{t}
$$

which implies that the individual cannot borrow against future income to increase consumption today. $W_{t}$ denotes financial wealth and $Y_{t}$ is income. The intertemporal budget constraint equals:

$$
W_{t+1}=\left(W_{t}-C_{t}+Y_{t}\right)\left(1+R^{f}+w_{t}\left(R_{t+1}-R^{f}\right)\right) .
$$

The portfolio return is given as

$$
R_{t+1}^{P}=1+R^{f}+\left(R_{t+1}-R^{f}-c\right) w_{t}
$$

where $c$ is the proportional fee for investing in stocks. Each period agents pay a fee and $c$ is a fixed percentage of the stock investment.

Furthermore I denote the wealth level after income and consumption as:

$$
A_{t}=W_{t}+Y_{t}-C_{t}
$$




\subsection{Financial market}

I consider a simple financial market with a constant interest rate $R^{f}$ and stocks with i.i.d. returns $R_{t+1}$. The stock returns, $R_{t+1}$, are normally distributed with an annual mean equity return $R_{f}+\lambda^{R}$ and a standard deviation $\sigma_{R}$, where $\lambda^{R}$ is the assumed "correct" equity risk premium. The agent is uncertain about the value of the equity premium. At time $t$, the agent merely has a distribution over the equity premium, $\lambda_{t}$. This distribution changes over time because of learning about the equity risk premium. The distribution of the equity risk premium, given the information at time $t$, is itself characterized by a state-variable, containing the learned mean $\lambda_{t}^{B}$, and its variance $\left(\sigma_{t}^{B}\right)^{2}$. Agents pay a proportional transaction fee, $c$, which differs per year. These fees generate time effects in stock allocation and allow the matching of the predictions from the model to the data. The parameters used are described in Section 2.6.

\subsection{Labor income process}

I assume that labor income is uncertain and given by

$$
Y_{t}=\exp \left(f_{t}+v_{t}+\epsilon_{t}\right) \text { for } t<K
$$

where

$$
v_{t}=v_{t-1}+u_{t}
$$

After the retirement age $K$ income is riskless and equals a fraction of the labor income at age 65 (the replacement rate). Labor income exhibits a hump-shaped profile over the life cycle which is accommodated by $f_{t}$, where $f_{t}$ is a deterministic function of age. The error term consist of a transitory component and a permanent component. $\epsilon_{t}$ is a transitory shock and is distributed as $N\left(0, \sigma_{\epsilon}^{2}\right)$. $u_{t}$ presents a permanent shock, where $u_{t} \sim N\left(0, \sigma_{u}^{2}\right)$. This representation follows Cocco, Gomes, and Maenhout (2005) and I calibrate the labor income process according to their estimates. The function $f_{t}$ is modeled by a third order polynomial in age,

$$
f_{t}=\alpha_{0}+\alpha_{1} t+\alpha_{2} t^{2} / 10+\alpha_{3} t^{3} / 100
$$

\subsection{Learning and updating of beliefs}

Agents learn about the equity risk premium during their lifetime and become less uncertain with age because they have received more information. I do not make assumptions about the cause of ambiguity about the equity risk premium. Uncertainty could stem from lack of statistical evidence, since stock market returns are so volatile that it is hard to measure the expected return. But 
uncertainty about the equity premium could also result from inconsistency is theoretical evidence or unsophistication of investors. As agents get older they update their beliefs on the equity risk premium conditional on the signals, i.e., realized returns. I assume agents update their beliefs irrespective of stock market participation, e.g., since everyone receives similar information via newspapers, television, and so on. Furthermore, the updating process for the set of priors follows from Bayes' rule. ${ }^{8}$

The agent is uncertain about the equity risk premium, $\lambda^{R}$. I model this as follows. Before observing any signals, the set of priors are normally distributed with mean $\lambda_{1}^{B}$ and variance $\left(\sigma_{1}^{B}\right)^{2}$. An individual of age $t$ has received $t-1$ independent signals about $\lambda^{R}, R_{t}=R^{f}+\lambda^{R}+\epsilon_{t}$, where $\epsilon_{t}$ is normally distributed with mean zero and a known variance $\sigma_{R}^{2}$. These signals, the realized excess returns, are observed annually. The updated priors about $\lambda^{R}$ is normally distributed with mean $\lambda_{t}^{B}$ and variance $\left(\sigma_{t}^{B}\right)^{2}$, where

$$
\begin{aligned}
\lambda_{t}^{B} & =\lambda_{1}^{B} \underbrace{\frac{\frac{1}{\left(\sigma_{1}^{B}\right)^{2}}}{\frac{1}{\left(\sigma_{1}^{B}\right)^{2}}+\frac{t-1}{\sigma_{R}^{2}}}}_{\text {weight mean prior }}+\frac{1}{t-1} \sum_{\tau=1}^{t-1}\left(R_{t}-R^{f}\right) \underbrace{\frac{\frac{t-1}{\sigma_{R}^{2}}}{\frac{1}{\left(\sigma_{1}^{B}\right)^{2}}+\frac{t-1}{\sigma_{R}^{2}}}}_{\text {weight returns }} \\
\left(\sigma_{t}^{B}\right)^{2} & =\frac{1}{\frac{1}{\left(\sigma_{1}^{B}\right)^{2}}+\frac{t-1}{\sigma_{R}^{2}} .}
\end{aligned}
$$

The posterior mean $\lambda_{t}^{B}$ is a precision weighted average of the prior mean and the average signal. At time $t=1$, representing age 20, the agent has not yet observed stock market returns. Unlike $\lambda_{t}^{B}$, the posterior variance $\left(\sigma_{t}^{B}\right)^{2}$ does not depend on the realizations of the signals. This variance, which measures the uncertainty/ambiguity about $\lambda_{R}$, decreases as the number of signals $t$ increases (learning reduces uncertainty), hence $\left(\sigma_{t}^{B}\right)^{2}<\left(\sigma_{t-1}^{B}\right)^{2}$.

Note that I do not assume that agents learn in a rational manner. People start with prior beliefs about the equity risk premium at age 20 and update those beliefs according to the realized returns from age 20 onwards. Hence agents put no weight on stock returns before age 20 and only take into account realizations during lifetime. Malmendier and Nagel (2010) find that stock returns experienced receive a much larger weight when forming beliefs about expected stock market returns compared to stock returns during childhood or before birth. The priors at age 20 could be thought of as containing to some extent the realized stock returns during before age 20, but I do not assume that prior beliefs at age 20 are equal to the confidence interval from the stock return data available.

Cohort effects can be identified by learning about the equity risk premium. For instance, a 25 year old in 2007 has faced 5 realized stock returns, and the mean of these excess returns $\left(R_{t}-R_{f}\right)$

\footnotetext{
${ }^{8}$ Other updating rules for beliefs are explored in Epstein, Noor, and Sandroni (2010), Epstein and Schneider (2007), and Hanany and Klibanoff (2009).
} 
induces a higher or lower beliefs compared to the prior mean belief about the equity premium, $\lambda_{1}^{B}$. If the updated belief, $\lambda_{6}^{B}$, has increased due to high realized stock returns, this can result in higher allocations to stocks. I calculate the pattern of stock allocations over the life cycle taking into account these cohort effects.

Two assumption are made: (1) the amount of ambiguity, $\sigma_{1}^{B}$, is the same for every 20-year old, independently of birth year and (2) the mean of the priors about the equity risk premium, $\lambda_{1}^{B}$, at age 20 is independent of birth year and hence independent of stock return realizations before age 20. In regard to assumption (1), the reason why I assume that the amount of ambiguity (standard deviation of belief) about the equity risk premium is the same in 1970 and 2000, is that data going back more than for instance 70 years may, according to the agent, not be that relevant for estimating the equity premium today, due to, for instance, structural changes (Pastor and Veronesi (2009)). Structural changes, induced by for example technologic innovations, might permanently change the equity risk premium. Hence the amount of uncertainty does not reduce over time and is thus irrespective of the year in which the agent is born.

Regarding assumption (2), the mean of the belief is the same for every 20-year old and does not depend on birth year. Different priors at age 20 could generate additional cohort effects, however I assume that the prior is independent of birth year, because agents incorporate realized stock returns during adult life more heavily into beliefs than returns during childhood or before birth, see Malmendier and Nagel (2010).

\subsection{Benchmark parameters for the life-cycle model}

I set the risk aversion coefficient $(\gamma)$ equal to 5, which is the same as used in Benzoni, CollinDufresne, and Goldstein (2007) and Gomes and Michaelides (2005). The ambiguity aversion parameter is assumed to be $10 .^{9}$ Time ranges from $t=1$ to time $T$, which corresponds to age 20 and 100 respectively. Agents retire at time $K=45$, corresponding to age 65 . The survival probabilities are the current male survival probabilities in the US which are obtained from the Human Mortality Database. ${ }^{10}$ I assume a certain death at age 100.

The correct equity premium $\lambda^{R}$ is assumed to be normally distributed with a annual mean of $4 \%$ and an annual standard deviation $\sigma_{R}$ of $16 \%$, which is in accordance with historical stock returns. The risk free rate is $2 \%$, hence the expected stock return is $6 \%$. The mean of the priors about the equity premium at time $t=1$ (age 20) is equal to the correct equity premium; $\lambda_{1}^{B}=4 \%$. The standard deviation of the beliefs at time $t=1, \sigma_{1}^{B}$, is $2 \%$.

\footnotetext{
${ }^{9}$ The literature on smooth recursive preferences is relatively new and requires as an input the ambiguity aversion parameter. As of yet only a few papers try to estimate this parameter and arrive at varying numbers. Chen, Ju, and Miao (2009) find values between 60 and 100, while Ju and Miao (2010) use a calibrated ambiguity parameter of 8.8.

${ }^{10} \mathrm{I}$ refer for further information to the website, www.mortality.org.
} 
I take the parameters for the labor income process estimated in Cocco, Gomes, and Maenhout (2005). The deterministic hump-shaped profile of income is generated by the parameters, $\alpha_{1}=$ 0.1682, $\alpha_{2}=-0.0323$, and $\alpha_{3}=0.002$. I choose the constant, $\alpha_{0}$ to accommodate different income levels at time $t=1$. The benchmark income level at age 20 is $\$ 15,000$. The variance of the transitory shock to labor income, $\sigma_{u}^{2}$, is $7.38 \%$ and the variance of the permanent shock, $\sigma_{\epsilon}^{2}$, is $1.06 \%$. The replacement rate of the labor income at age 65 is $68 \%$ of the wage at age 65 . The income during retirement is riskless. These numbers are for a high school graduate which are estimated in Cocco, Gomes, and Maenhout (2005) and used as the benchmark parameters in their analysis.

\subsection{The individuals optimization problem and numerical method}

The timing, during one year, is as follows, first an individual receives his labor or retirement income after which he consumes. Subsequently the remaining wealth is invested. I assume the investor is liquidity constraint and impose standard borrowing and short-sales constraints.

The optimization problem is solved via dynamic programming and I proceed backwards to find the optimal investment and consumption strategy. In the last period the individual consumes all his remaining wealth, hence his utility from terminal wealth is known.

\subsubsection{Solving maximin preferences}

Due to the richness and complexity of this model it cannot be solved analytically, so I employ numerical techniques following Brandt, Goyal, Santa-Clara, and Stroud (2005) and Carroll (2006) with several extensions by Koijen, Nijman, and Werker (2010). Brandt, Goyal, Santa-Clara, and Stroud (2005) adopt a simulation-based method which can deal with many exogenous state variables. In this model, the mean of the priors about the equity premium, $\lambda_{t}^{B}$, and income, $Y_{t}$, are the relevant exogenous state variables. Wealth acts as an endogenous state variable. For this reason, following Carroll (2006), I specify a grid for wealth after income and consumption. As a result, I do not need numerical rootfinding to obtain the optimal consumption decision.

In each period I find the optimal asset weights by setting the first order condition equal to zero

$$
\mathbb{E}_{t}^{\lambda_{t}^{\min }}\left(C_{t+1}^{*-\gamma}\left(R_{t+1}-R^{f}\right)\right)=0
$$

where $\lambda_{t}^{\min }$ is the lowest equity premium in $\Lambda_{t} . C_{t+1}^{*}$ denotes the optimal consumption level. The optimal consumption follows from

$$
C_{t}^{*-\gamma}=\beta p_{t+1} \mathbb{E}_{t}^{\lambda_{t}^{m i n}}\left(C_{t+1}^{*-\gamma} R_{t+1}^{P *}\right)
$$


The numerical method I use to solve the life-cycle problem with maximin preferences is described in Appendix A.

\subsubsection{Solving recursive smooth preferences}

In each period I find the optimal asset weights by setting the first order condition equal to zero

$$
\begin{aligned}
\frac{\partial V_{t}}{\partial w_{t}}= & \beta\left(\phi^{-1}\right)^{\prime}\left(\int_{\Lambda_{t}}\left\{\phi\left(\mathbb{E}_{t}^{\lambda}\left\{V_{t+1}\left(W_{t+1}\right)\right\}\right)\right\}\right) \\
& \int_{\Lambda_{t}}\left\{\phi^{\prime}\left(\mathbb{E}_{t}^{\lambda}\left\{V_{t+1}\left(W_{t+1}\right)\right\}\right) \mathbb{E}_{t}^{\lambda}\left\{C_{t+1}^{*-\gamma}\left(R_{t+1}-R^{f}\right)\right\}\right\}=0
\end{aligned}
$$

where $\mathbb{E}_{t}^{\lambda}$ is the expectation, conditional on the values of the state variables at time $t$. I take the weighted mean over the distorted expected utilities. Because the optimization problem is solved via backwards recursion, I know $C_{t+1}^{*}$ at time $t+1$. Furthermore, I simulate the exogenous state variables for $\mathrm{N}$ trajectories and $\mathrm{T}$ time periods to calculate the realizations of the Euler condition (20). I regress these realizations on a polynomial expansion in the state variables to obtain an approximation of the conditional expectation of the Euler condition.

The optimal consumption at time $t$ follows from

$$
\begin{aligned}
C_{t}^{*-\gamma}= & \beta\left(\phi^{-1}\right)^{\prime}\left(\int_{\Lambda_{t}}\left\{\phi\left(\mathbb{E}_{t}^{\lambda}\left\{V_{t+1}\left(W_{t+1}\right)\right\}\right)\right\}\right) \\
& \int_{\Lambda_{t}}\left\{\phi^{\prime}\left(\mathbb{E}_{t}^{\lambda}\left\{V_{t+1}\left(W_{t+1}\right)\right\}\right) \mathbb{E}_{t}^{\lambda}\left\{C_{t+1}^{*-\gamma} R_{t+1}^{p}\right\}\right\} .
\end{aligned}
$$

\section{Effect of ambiguity aversion and learning on optimal alloca- tions with maximin preferences}

\subsection{Age effect of ambiguity aversion on optimal portfolio choice}

In the benchmark life-cycle model, age effects are generated by ambiguity aversion, learning, and labor income and in this section I focus only on these age effects. Furthermore, in this section fees are excluded from the analysis. The optimal fraction allocated to stocks, conditional on participation in the stock market is graphed in Figure 1a. The slight non-smoothness of the curves in the figures are due to simulation inaccuracy. Comparing the case with ambiguity (solid line) to no ambiguity (dashed line), shows that the allocation to stocks when agents are ambiguity averse is much lower. The impact of ambiguity aversion is substantial at young ages, but this effect declines at later ages. This is intuitive, since the ambiguity about the equity risk premium decreases over time as agents learn. 


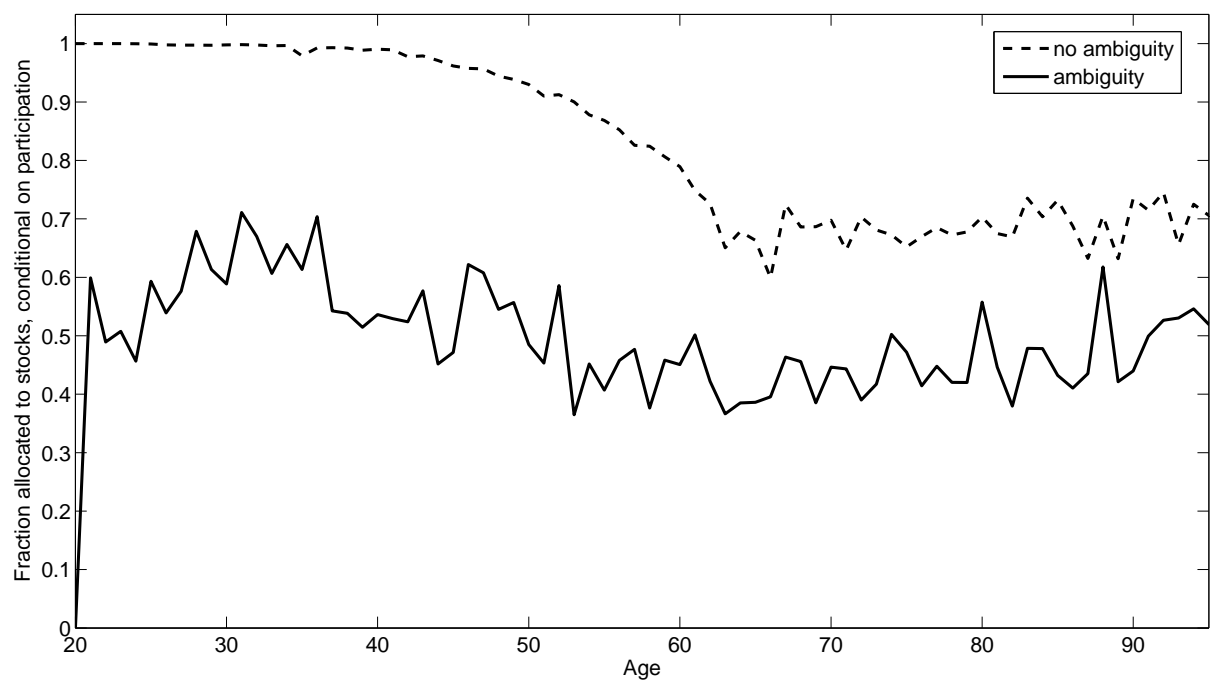

(a) Fraction allocated to stocks, conditional on participation

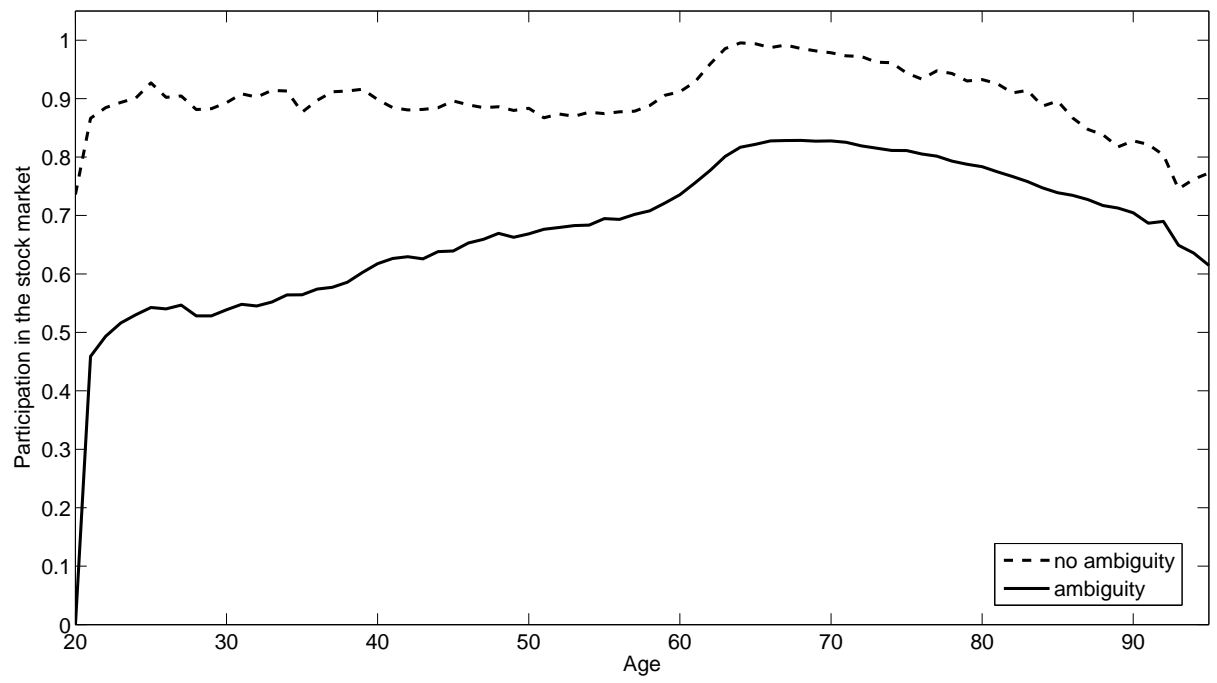

(b) Stock market participation

Figure 1: Optimal fraction allocated to stocks and optimal participation in the stock market.

I display the optimal conditional fraction of financial wealth allocated to stocks and optimal participation in the stock market for agents who are (1) ambiguous about the equity risk premium and learn about this parameter and who are (2) not ambiguous about the equity premium. The upper panel shows the fraction of financial wealth allocated to stocks, conditional on stock market participation. The lower panel shows the optimal participation level, which is unconditional on having positive financial wealth, and thus includes all the simulation paths. In case an agent has a near zero financial wealth level (below \$100), the optimal participation is assumed to be zero. Agents learn about the equity risk premium. Maximin preferences are used and the parameters are as in the benchmark case, unless stated otherwise. 
Focussing on the no-ambiguity case, if agents are fully certain about the values of all the parameters in the model, they allocate $100 \%$ of financial wealth to stocks before age 40 . Similar results are found in Cocco, Gomes, and Maenhout (2005). The reason for this high fraction is that young agents have only a small amount of financial wealth compared to a high level of human capital. Since human capital is like an implicit investment in a riskless asset, an agent allocates optimally his entire financial wealth to equity. Between age 40 and 65 the conditional allocation to the risky asset decreases. At those ages retirement savings are very high while at the same time the net present value of labor income decreases, hence the fraction of financial wealth to human capital increases. This results in a decline of the relative allocation to the riskless asset "human capital" and, as a consequence, the optimal fraction of financial wealth invested in stocks decreases to maintain a similar risk-profile. After retirement the allocation to stocks increases slightly, as in Cocco, Gomes, and Maenhout (2005). At that time the agent depletes his financial wealth more rapidly due to the additional implicit discount factor, survival probabilities, and hence the fraction of financial wealth to human capital decreases, which induces a higher fraction of financial wealth invested in stocks. If agents are ambiguous about the equity risk premium, they allocate less financial wealth to stocks. At all ages the fraction allocated to stocks is approximately $50 \%$, which is much closer to the empirical findings.

Figure $1 \mathrm{~b}$ displays the effect of ambiguity about the equity risk premium, and aversion with respect to this ambiguity, on optimal participation levels in the stock market. The effect is substantial, the participation level before retirement drops by about $25 \%$ on average. When agents are not ambiguous about the equity premium, the participation levels in the stock market are high. Since labor income is not correlated with returns on the stock market, it is optimal for all agents, even with low financial wealth, to allocate at least a small fraction of financial wealth to stocks. ${ }^{11}$ The reason that not $100 \%$ participates is that I assume that agents with financial wealth below $\$ 100$ do not invest in stocks. If I would take these agents with near zero wealth into account it would distort the comparison of the model predictions to the data since in reality people with less than $\$ 100$ would not invest, due to participation costs and minimum balance requirements. ${ }^{12}$ The impact of ambiguity aversion decreases with age since the ambiguity about the equity risk premium declines, as agents learn by observing the realized stock returns. Cao, Wang, and Zhang (2005) and Easley and O'Hara (2009) find that ambiguity aversion can limit the participation levels, both in a non-life-cycle framework.

\footnotetext{
${ }^{11}$ I abstract from hedging demand. The investment opportunities improve slightly after a high realized stock return, which could induce a negative hedging demand. But since the size of the update of the mean belief about the equity risk premium is very small, the hedging demand will be neglible. So I set the stock market participation equal to zero if the worst case belief is zero or negative.

${ }^{12}$ In addition, the simulation inaccuracy of optimal stock allocations is higher for these low wealth levels, since the difference in utility of the agent when he invest $100 \%$ or $0 \%$ in stocks is negligible.
} 
Whether agents participate in the stock market depends only on the worst case belief about the equity risk premium. If the worst case belief is zero or negative, the agent does not participate in the stock market, while if the worst case equity risk premium is positive, the agent participates. Even if the agent has not that much wealth, if the worst case belief is positive, the agent optimally invests a positive fraction of his wealth to stocks. The reason why no ambiguity averse agent participates at age 20 is that the worst case belief is exactly zero. At age 20 all agents have a mean belief about the equity risk premium of $4 \%$ and a standard deviation of $2 \%$. The $95 \%$ confidence interval, which is the range of beliefs that the agent considers, is $[0 \%, 8 \%] \cdot{ }^{13}$ Hence the worst case belief is $0 \%$, which results in zero participation in the stock market. The worst case beliefs are presented in Figure 2. At age 21 the agent has experienced a stock return realization at age 20, and updates his belief. In the figure it can be seen that the $50 \%$ quantile is higher than $0 \%$, hence more than $50 \%$ of agents participates in the stocks market.

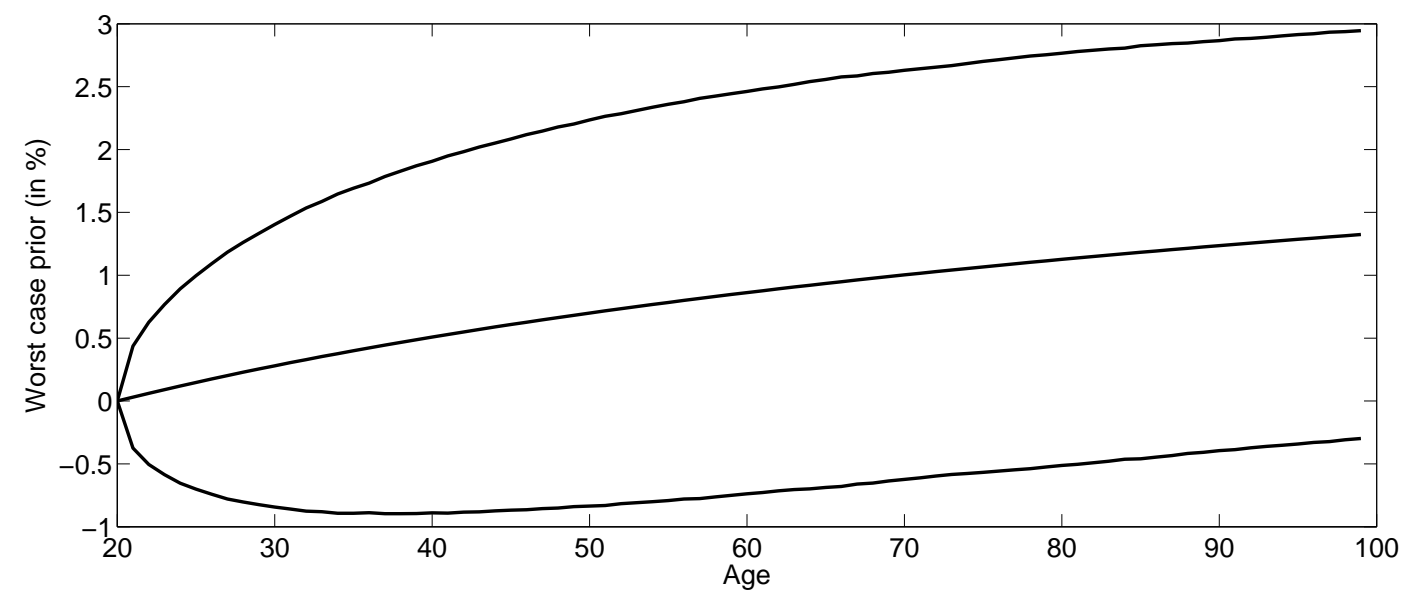

Figure 2: The worst case prior about the equity risk premium; mean, 5th and 95th percentile. In this figure I display the worst case beliefs about the equity risk premium. The agent maximizes his utility as if the worst case belief is the correct parameter. The worst case belief at age 20 is $0 \%(4 \%-2 * 2 \%)$. When people age, they update the beliefs (mean and standard deviation) according to the realized stock returns, hence the worst case beliefs are different per trajectory. The parameters are as in the benchmark case, unless stated otherwise.

Vissing-Jorgenson (2002) and Paiella (2001) examine the implications of fixed participation costs on optimal participation levels and find that it can explain why less wealthy household do not participate, but not the low participation levels of the wealthy. I find that ambiguity about the equity risk premium can provide an explanation for the lower participation levels of wealthy individuals. The benchmark model with ambiguity aversion and learning does however predict some extreme participation levels if I take into account cohort effects induced by learning. If, for instance, the worst case belief of all 30-year olds in 2007 is positive, this results in 100\% participation of all 30 -year olds in 2007 . However, this hinges on the assumption that the ambiguity about the equity

\footnotetext{
${ }^{13}$ I do not take the exact $95 \%$ confidence interval, which would be $[4 \%-1.96 * 2 \%, 4 \%+1.96 * 2 \%]$.
} 
risk premium, i.e., the mean and the standard deviation of the beliefs, is exactly the same for all 30 -year olds in 2007. Assuming heterogeneity of beliefs at age 20, would change this result.

In the previous paragraphs, the optimal allocation is explored for agents who are ambiguous and are averse to this ambiguity. In contrast, in the more standard ambiguity neutral framework agents are only uncertain about the parameters, but not averse with respect to this uncertainty. When this is the case, the optimal allocation will almost not change. In the benchmark model, the agents' beliefs about the equity risk premium are normally distributed with a mean of $4 \%$ and a standard deviation equal to $2 \%$. If agents are ambiguity neutral, their behavior is induced by the so called predictive distribution. The standard deviation for the compound distribution of the volatility of the return on equity, $\sigma_{R}$ and the volatility of the belief, $\sigma_{t}^{B}$, can be reduced to the predictive volatility $\sqrt{\sigma_{R}^{2}+\left(\sigma_{t}^{B}\right)^{2}}$. For the benchmark parameters this results in a standard deviation of $16.1 \%$ (note that $\sigma_{R}$ is $16 \%$ ). Hence uncertainty about the equity risk premium will have (almost) no effect on optimal portfolio choices when assuming uncertainty neutrality. I do not graph these results here, but the optimal fraction allocated to stocks and optimal participation levels are almost indistinguishable from the dashed-lines in Figure 1, the no-ambiguity case.

\subsection{Comparing the optimal stock allocations to the empirical evidence}

In this section I compare the predictions from my benchmark life-cycle model with the data from the Survey of Consumer Finances. The Survey of Consumer Finances is the most comprehensive dataset on households assets and liabilities in the United States. The survey is conducted every three years since 1983. From 1983 to 1989 it is partly a panel dataset, while after 1989 the data consists of repeated cross sections. High income household are over-sampled to obtain a sufficient number of wealthy households in the study. I employ a measure for financial wealth and stock investment according to the method suggested by the survey of consumer finances. The same measures are used in Gomes and Michaelides (2005). Financial wealth consists of both retirement and non-retirement wealth and stock investment is calculated as the sum of direct investment in stock and stock mutual funds as well as stock investment of pension wealth. More details on the data from the Survey of Consumer Finances can be found in Appendix B.

Agents behave according to maximin preferences and face ambiguity about the equity risk premium. Previously I only examined the age effects of ambiguity aversion and learning, while in this section time and cohort effects are included. First, I will compare the model predictions to the data, where the model predictions include age and time effects, but exclude cohort effect. Thus assuming that cohort effects are zero. Time effects are induced by introducing decreasing proportional fees over time. Subsequently, I will include cohort effects to explore which model specification fits the data best. 


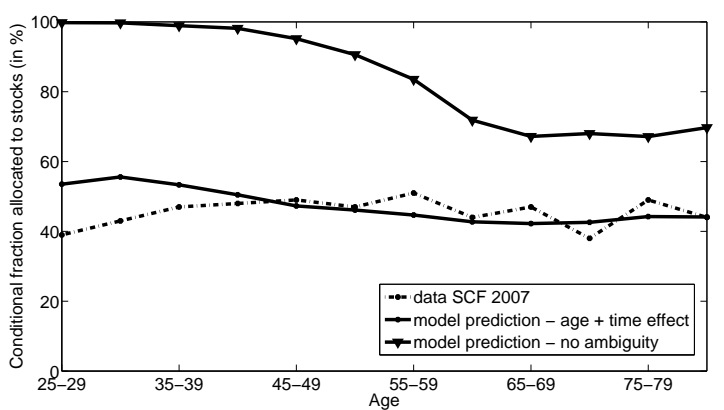

(a) Conditional fraction allocated to stocks in 2007

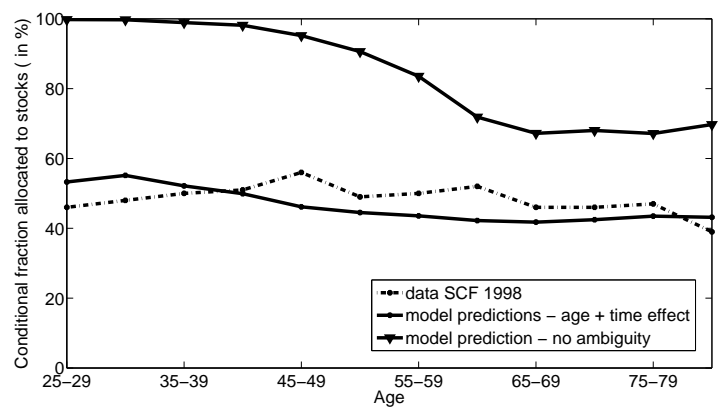

(c) Conditional fraction allocated to stocks in 1998

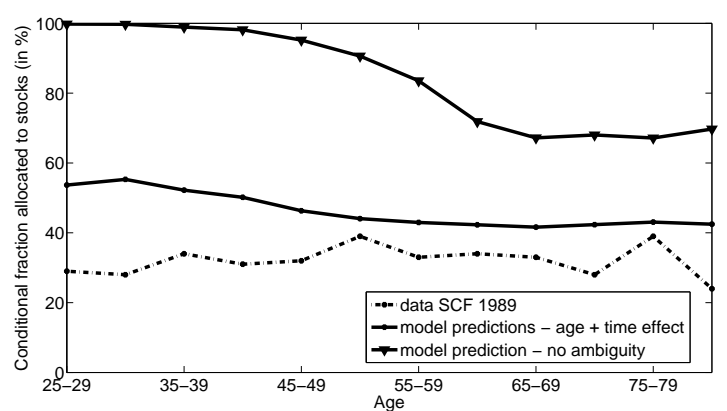

(e) Conditional fraction allocated to stocks in 1989

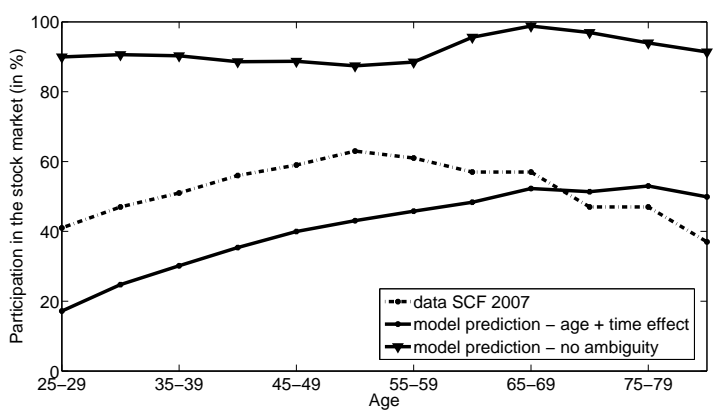

(b) Stock market participation in 2007

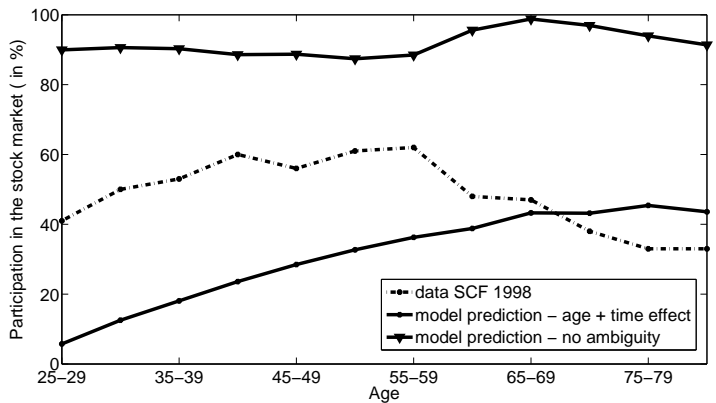

(d) Stock market participation in 1998

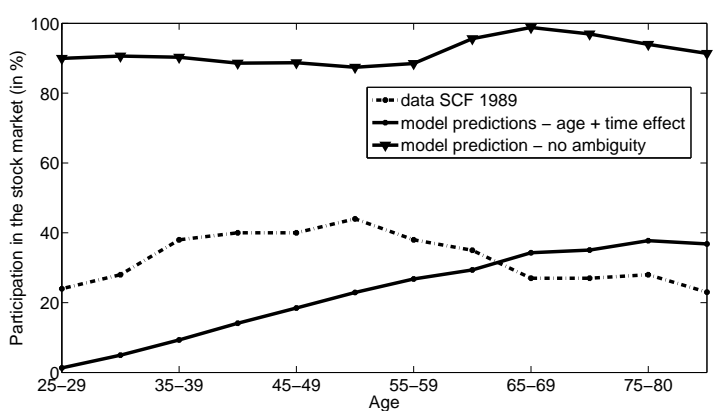

(f) Stock market participation in 1989

Figure 3: Comparing the empirical data to the model predictions on stock allocations; age and time effects included.

I display the conditional fraction of financial wealth allocated to stocks and the optimal stock market participation both for the data and the optimal levels. The fraction of financial wealth allocated to stocks is conditional on stock market participation. The optimal participation level is unconditional on having positive financial wealth, and thus includes all the simulation paths. In case an agent has a near zero financial wealth level (below \$100), the optimal participation assumed to be zero. Agents learn about the equity risk premium. The fees in 2007, 1998, and 1989 are 50,100, and 150 basispoints respectively. The data are repeated cross sections from the Survey of Consumer Finances, and I take averages over the fraction allocated to stocks, conditional on participation. Maximin preferences are used and the parameters are as in the benchmark case, unless stated otherwise. 
Panel (a), (c), and (e) in Figure 3 shows the effect of ambiguity aversion on the optimal fraction allocated to stocks, conditional on stock market participation, and compares the model predictions with the empirical levels. As before, ambiguity about the equity risk premium has a substantial impact on the fraction of financial wealth allocated to stocks. The average fraction allocated to stocks over the life cycle when agents are not ambiguous is approximately $85 \%$, while if ambiguity aversion is included, the average fraction to stocks equals $50 \%$. When comparing the predictions from the life cycle model with ambiguity aversion and learning to the data, the match is much better. To compare, Gomes and Michaelides (2005) find optimal allocation levels of almost 100\% at young ages, while the model with ambiguity predicts optimal levels of about $55 \%$. Note, that the model predictions for the conditional fraction allocated to stocks is almost the same in 2007, 1998, and 1989. The reason is that, conditional on the worst case belief being is positive (i.e., conditional on participation), the average of the worst case beliefs for all the trajectories at a certain age are approximately the same. However, the fraction of agents that have positive worst case beliefs (the participation levels) depends highly on the size of the fees. This can be seen in panel (b), (d), and (f); the participation levels are much higher in 2007 compared to 1989. Due to fees, the worst case beliefs about the equity risk premium are lowered with this exact percentage and hence the optimal participation levels shift down. The inclusion of time effects, which I assume arise (mostly) due to fees, allows the matching of the participation levels in 2007, 1998, and 1989, since in 1989 the empirical participation levels are substantially lower. In sum, the model with ambiguity about the equity risk premium matches more closely to the data than the model without ambiguity aversion.

It is difficult empirically to separate the effects of age, cohort, and time on portfolio choice. The intrinsic identification problem prevents inclusion of unrestricted age, time, and cohort effects. However, under certain assumptions, the structural model in this paper does allow the identification of all three effects. In previous sections, the age and time effects on portfolio choice are presented, which are generated by ambiguity about the equity premium and learning as well as labor income. These results are unconditional on the history of stock returns. However, realizations of past stock returns, which differ among cohorts, can potentially induce cohort effects in the data. Malmendier and Nagel (2010) find that stock market return experiences during life influence the beliefs about expected stock returns. The beliefs about the equity premium for varying ages in the years 2007, 1998, and 1989 are presented in Figure 4. The beliefs of an agent are determined in part by the mean of the priors at age 20 and in part by the realizations of stock returns. Figure 4 shows that the mean of the belief for a 25-29 year old is about $4.5 \%$ in 1998 and 3.7\% in 2007. The difference stems from the fact that the 25-29 year old in 1998 experienced some very good returns in the early and mid 90's, while the agent born later experienced low returns in the early 21 st century. The deviations of the mean belief about the equity risk premium from $4 \%$ generates and allows the identification of cohort effects. 


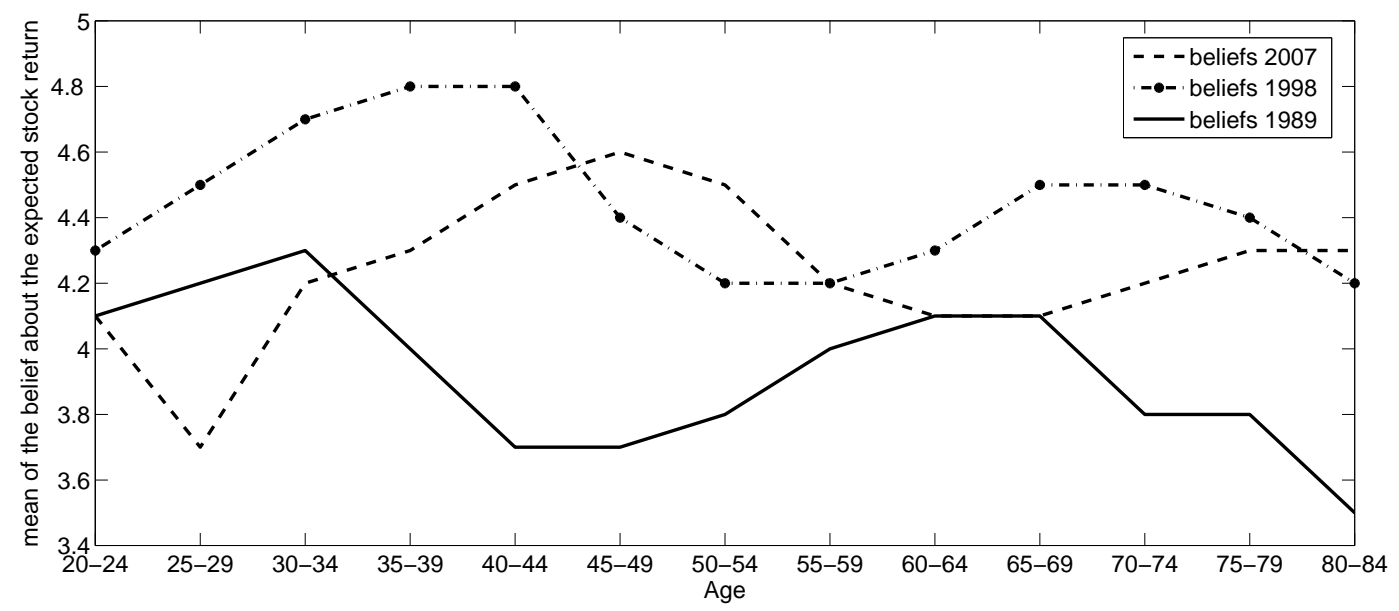

Figure 4: Beliefs about the equity risk premium in the years 2007, 1998, and 1989.

The graph reports the beliefs for different ages in the years 2007, 1998, 1989. The mean of the priors about the equity risk premium, $\lambda^{B}$ is displayed, not the worst case prior. To obtain these figures I used the realized stock returns downloaded from Robert Shillers' website (http://www.econ.yale.edu/ shiller/data.htm), which contains US stock market data from 1871 onwards. To calculate the belief for a 25 year old in 2007 I combine the prior belief with the average of returns in 2003 to 2006. The mean of the belief for age 25-29 is the average of the beliefs for a 25 year old agent, 26-year old, and so on.

Figure 5 compares the predictions from the model with (1) age and time effects and (2) age, time, and cohort effects to the data. First of all, the match is better when cohort effects are assumed to be zero. When examining the optimal participation levels in 1989, panel (f), the model predictions when including cohort effects are zero participation at all ages. The reason is that at all ages, the worst case belief (mean belief minus fees minus two times the standard deviation of beliefs) is always negative, which induces zero participation. Furthermore, the conditional fraction allocated to stocks is lower when cohort effects are included, compared to excluding cohort effects. This is not per definition the case, but the reason is that the average worst case beliefs over all the trajectories (so excluding cohort effects), conditional on positive beliefs, is higher than the worst case beliefs at all ages in 2007, 1998, and 1989.

In the previous graphs, I focussed on matching the means of the participation levels and the conditional allocation to stocks, not examining other moments. Table 1 displays the stock allocations predicted by the model and empirical estimates for different quantiles, assuming that cohort effects are zero. The $10 \%$ quantile of the fraction allocated to stocks for all ages is $10 \%$ in the data and $7 \%$ according to the model. The median matches very well, $45 \%$ of financial wealth allocated to stocks in the data compared to $43 \%$ according to the model. When splitting the fraction invested in stocks up for different ages, the quantiles in the data differ slightly more from the model predicted quantiles. Note that it is not insightful to present the quantiles for the participation levels, since this is a $0 / 1$ variable and all the information is already contained in Figure 5, where the mean 


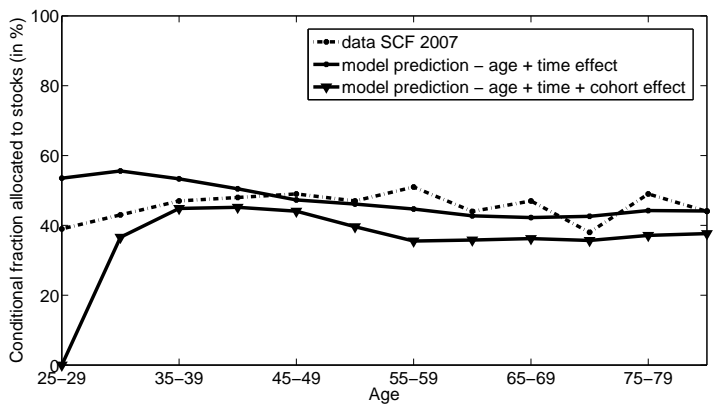

(a) Conditional fraction allocated to stocks in 2007

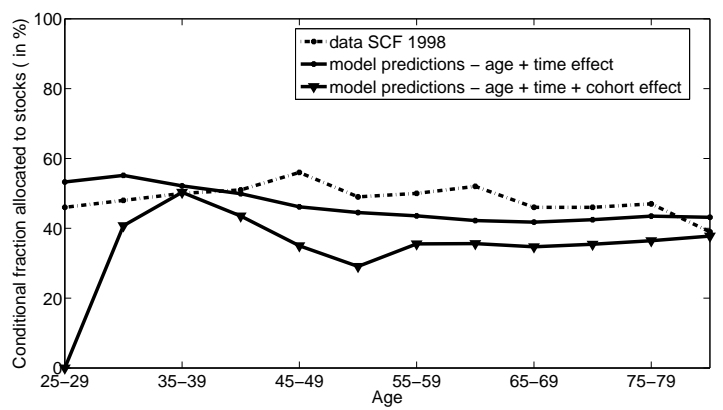

(c) Conditional fraction allocated to stocks in 1998

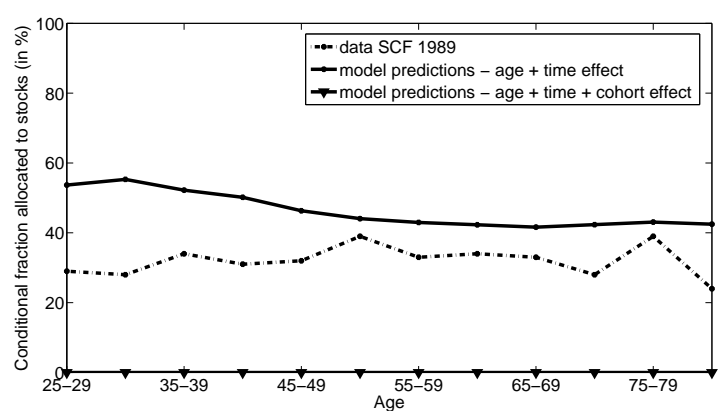

(e) Conditional fraction allocated to stocks in 1989

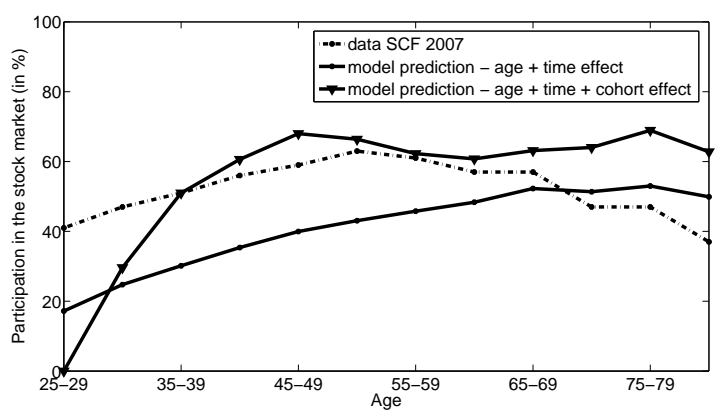

(b) Stock market participation in 2007

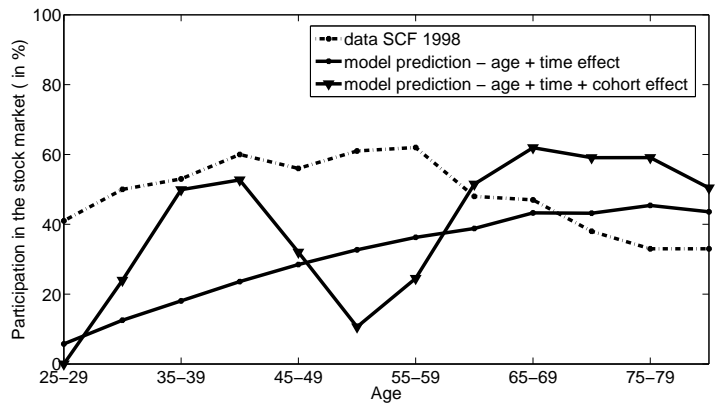

(d) Stock market participation in 1989

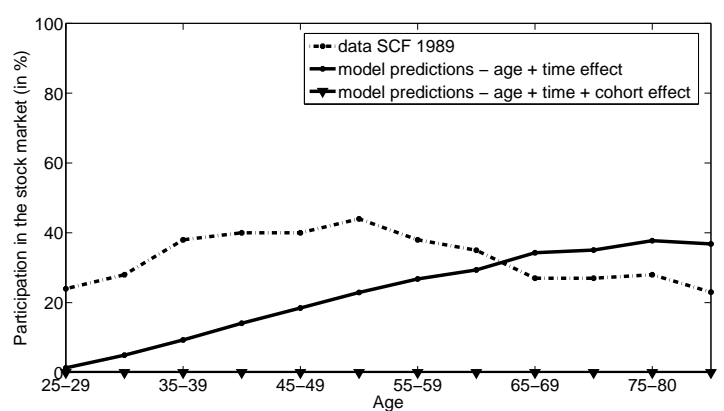

(f) Conditional fraction allocated to stocks in 1998

Figure 5: Comparing the empirical data to the model predictions on stock allocations; age, time, and cohort effects included.

I display the conditional fraction of financial wealth allocated to stocks and the optimal stock market participation both for the data and the optimal levels. The fraction of financial wealth allocated to stocks is conditional on stock market participation. The optimal participation level is unconditional on having positive financial wealth, and thus includes all the simulation paths. In case an agent has a near zero financial wealth level (below \$100), the optimal participation assumed to be zero. Agents learn about the equity risk premium. Cohort effects are included and the fees in 2007, 1998, and 1989 are 50,100, and 150 basispoints respectively. The data are repeated cross sections from the Survey of Consumer Finances, and I take averages over the fraction allocated to stocks, conditional on participation. Maximin preferences are used and the parameters are as in the benchmark case, unless stated otherwise. 
Table 1: Quantiles for the optimal and empirical conditional fraction of financial wealth allocated to stocks; age and time effects included.

The conditional fraction allocated to stocks in 2007 are calculated via the Survey of Consumer Finances. The optimal fraction is calculated including, age and time effects. Fees of 50 basispoints are included. Both the optimal and the empirical fraction are conditional on stock market participation.

\begin{tabular}{l|ccccc}
\hline \hline Data & 10\% quantile & 25\% quantile & 50\% quantile & 75\% quantile & 90\% quantile \\
\hline age 25-74 & 10 & 23 & 45 & 69 & 88 \\
\hline age 25-34 & 7 & 17 & 36 & 65 & 87 \\
age 35-44 & 10 & 23 & 45 & 72 & 88 \\
age 45-54 & 14 & 26 & 47 & 68 & 88 \\
age 55-64 & 11 & 26 & 47 & 68 & 90 \\
age 65-74 & 6 & 18 & 37 & 70 & 88 \\
\hline \hline Model & $10 \%$ quantile & $25 \%$ quantile & $50 \%$ quantile & $75 \%$ quantile & $90 \%$ quantile \\
\hline age $25-74$ & 7 & 20 & 43 & 82 & 100 \\
\hline age 25-34 & 10 & 27 & 60 & 99 & 100 \\
age 35-44 & 10 & 23 & 51 & 94 & 100 \\
age $45-54$ & 8 & 19 & 40 & 78 & 100 \\
age 55-64 & 5 & 14 & 33 & 72 & 100 \\
age $65-74$ & 6 & 14 & 30 & 67 & 100 \\
\hline \hline
\end{tabular}

participation levels are displayed.

\subsection{Effect of ambiguity aversion on optimal consumption and savings}

The optimal consumption and wealth decisions are plotted in Figure 6. The difference between the consumption levels when agents are ambiguous about the equity risk premium is substantial: the consumption of agents who are ambiguity averse is 5-10\% lower from age 30 onwards. The reason is that agents who are ambiguous about the equity risk premium, invest less in equity and, as is displayed in Figure 6b, have less wealth (savings plus investment return) accumulated. Furthermore, note that the consumption pattern is smooth over time, while the real income drops substantially at retirement because the replacement rate is 0.68, in line with Cocco, Gomes, and Maenhout (2005). The agent saves to obtain a smooth consumption pattern over life, which can be seen in Figure 6b. Agents who face ambiguity about the equity risk premium have a lower amount of wealth accumulated at age $65, \$ 225,000$ compared to $\$ 250,000$, since on average less agents participate in the stock market and the agents that participate invest a smaller fraction of their financial wealth in stocks. The savings levels are comparable to the findings in Cocco, Gomes, and Maenhout (2005). 


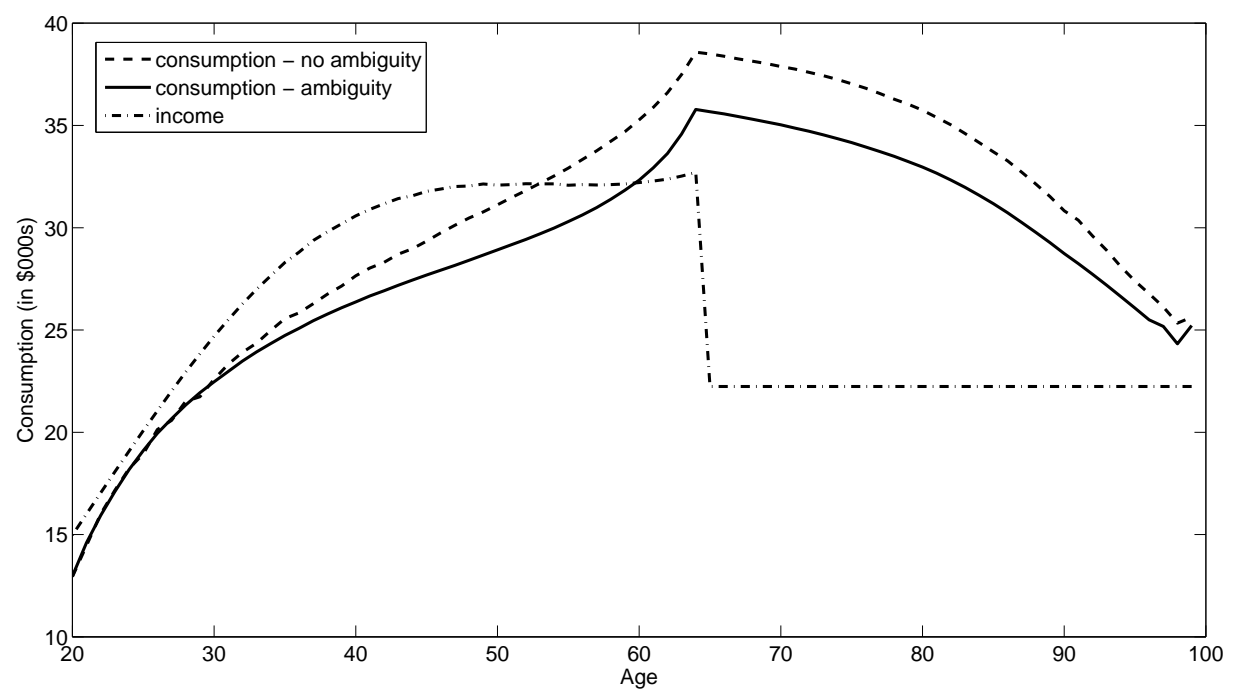

(a) Optimal consumption

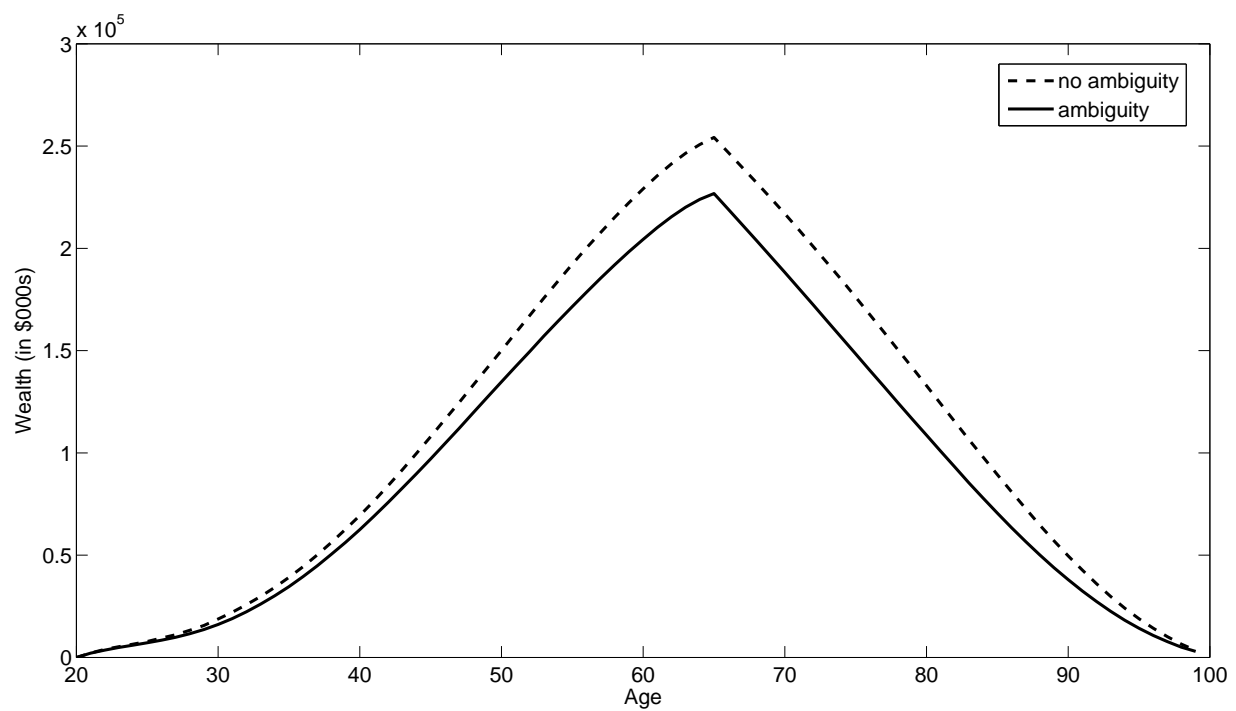

(b) Optimal wealth

Figure 6: Optimal consumption and wealth.

I display the average optimal consumption and optimal wealth for agents who are (1) ambiguous about the equity risk premium and who are (2) not ambiguous. Furthermore the average income is presented, which is independent of whether agents are ambiguous. Maximin preferences are used and the parameters are as in the benchmark case, unless stated otherwise.

\section{The Effect of Ambiguity Aversion and Learning on Optimal Portfolio Choice with Smooth Preferences}

In the previous section I show that when agents have maximin preferences, ambiguity aversion has a large effect on optimal portfolio choices. However, there is considerable debate on whether 
agents exhibit smooth preferences or maximin preferences hence in this section I examine the influence of ambiguity aversion when agents behave according to smooth recursive preferences with moderate ambiguity aversion. Note that smooth ambiguity preferences with infinite ambiguity aversion equals maximin preferences.

Klibanoff, Marinacci, and Mukerji (2005) express that one of the advantages of smooth recursive preferences is that ambiguity, the amount of uncertainty about the parameter, can be distinguished from the aversion to this ambiguity. Figure 7a shows the optimal fraction of financial wealth allocated to stocks, conditional on participation in the case that (1) the parameters are not ambiguous and (2) the parameters are moderately ambiguous and the agent is averse to this ambiguity. There is a small decrease in the allocation to stocks. When comparing the curves in Figure $7 \mathrm{~b}$, I find that the participation levels do not vary much with the level of ambiguity. Independent of whether the agent is uncertain, the participation levels are high. Overall, for the benchmark parameters the effect of ambiguity aversion on the optimal portfolio allocation is negligible.

The finding that ambiguity aversion has (almost) no effect on optimal portfolio choice for the benchmark parameters and smooth recursive preferences with moderate ambiguity aversion $(\alpha=$ 10), is confirmed by the analytical optimal portfolio choice solution found in Gollier (2009). He derives the optimal solution in a static model for an exponential specification for the risk aversion function and a power specification for the ambiguity aversion function. In contrast, I use a powerexponential specification and no analytical solution can be derived in that case. Gollier (2009) finds the following optimal solution:

$$
w^{*}=\frac{\lambda^{B}}{\gamma\left(\sigma_{R}^{2}+(1+\alpha)\left(\sigma_{t}^{B}\right)^{2}\right)},
$$

and when I plug in the benchmark parameters at $t=1$ the equation equals:

$$
w^{*}=\frac{0.04}{\gamma(0.0256+(1+\alpha) 0.0004)} \text {. }
$$

The optimal allocation to equity, $w^{*}$, depends only little on the ambiguity aversion parameter, $\alpha$, which is comparable to the findings in this paper. Similarly, Chen, Ju, and Miao (2009) explore the impact of model uncertainty about return predictability on asset allocation, and find that the risk aversion parameter has a larger effect on optimal portfolio choice than ambiguity aversion. In contrast, Klibanoff, Marinacci, and Mukerji (2005) illustrate the possible effect of ambiguity on portfolio choice in a static example and find a sizeable effect. However the amount of uncertainty is higher compared to the benchmark case in this paper.

The optimal stock allocation for an ambiguity aversion parameter between 10 and infinity is not yet calculated. In the limit when ambiguity aversion goes to infinity the effect of ambiguity about 


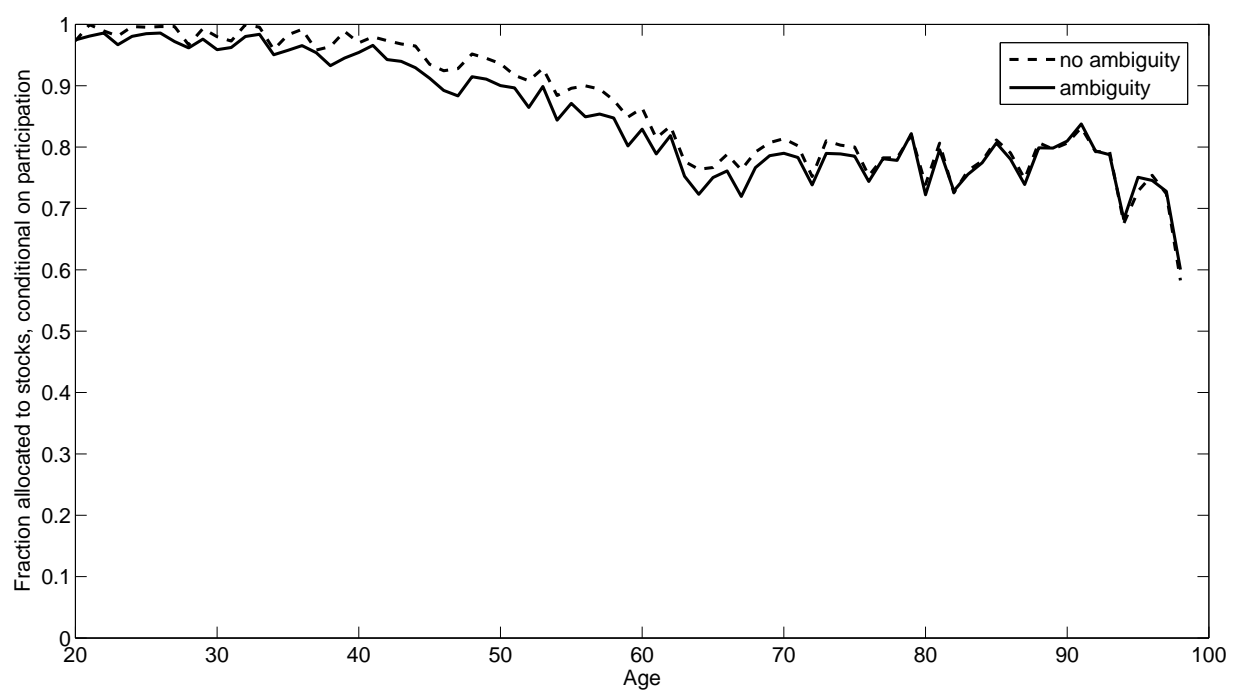

(a) Fraction allocated to stocks, conditional on participation

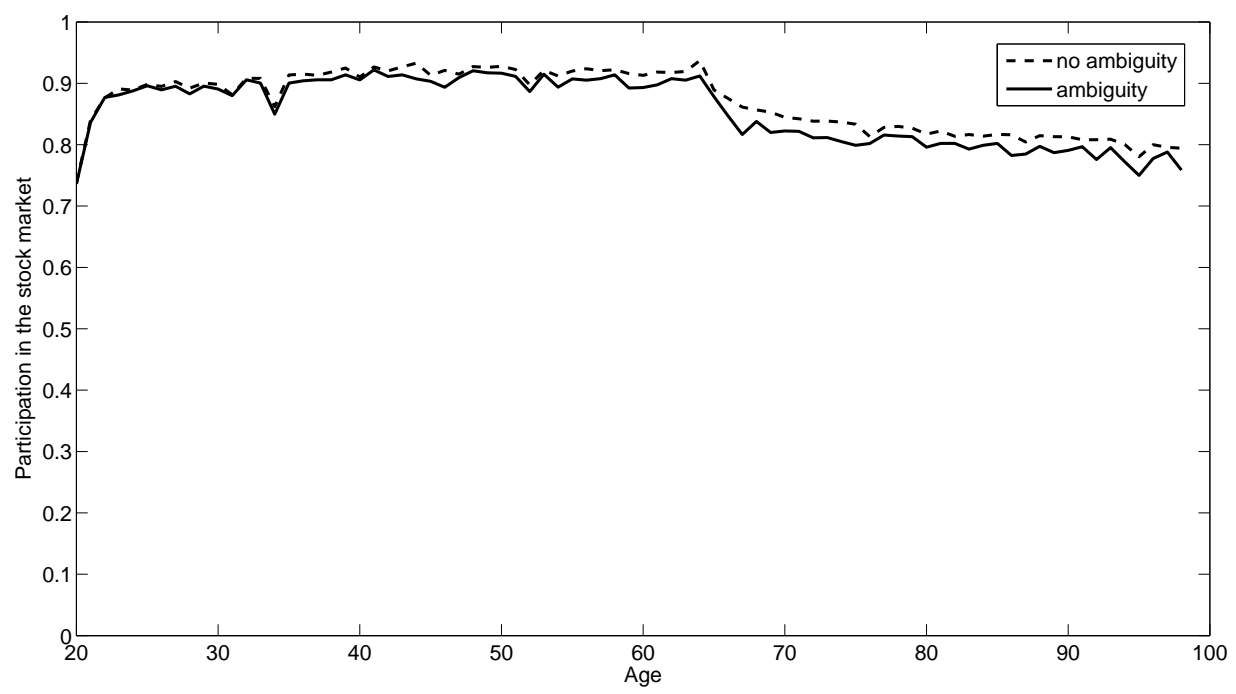

(b) Stock market participation

Figure 7: Conditional fraction allocated to stocks and stock market participation

I display the optimal conditional fraction of financial wealth allocated to stocks and optimal participation in the stock market for agents who are (1) ambiguous about the equity risk premium and learn about the parameters and who are (2) not ambiguous about the equity premium. The upper panel shows the fraction of financial wealth allocated to stocks, conditional on stock market participation. The lower panel shows the optimal participation level, which is unconditional on having positive financial wealth, and thus includes all the simulation paths. In case an agent has a near zero financial wealth level (below \$100), the optimal participation is set to zero. Agents learn about the equity risk premium. Smooth recursive preferences are used and the parameters are as in the benchmark case, unless stated otherwise. 
the equity risk premium is sizeable and can help explain the empirically observed low allocation to stocks. However, for which ambiguity aversion coefficient in the smooth preferences framework this similar result is achieved is not yet examined. Consistent with the findings in this paper, experimental evidence suggests that agents behave more according to kinked (maximin) preferences than smooth ambiguity preferences (see Ahn, Choi, Gale, and Kariv (2010)).

\section{Importance of income, risk aversion, and initial ambiguity with minimax preferences}

In this section the importance of several assumptions for the main results are tested; assumptions on (1) the level of initial ambiguity about the equity premium, (2) the level of risk aversion, and (3) labor income. Since the effect of ambiguity aversion if agents have smooth preference with moderate risk aversion is limited, I will focus the robustness tests on maximin preferences. In Section 5.4, I explore whether increasing risk aversion can substitute for ambiguity aversion, and change the optimal stock allocation in a similar way.

\subsection{Initial ambiguity about the equity risk premium}

The amount of ambiguity, the standard deviation of the belief about the equity risk premium, is chosen somewhat arbitrarily. There is no direct evidence on which to base the level of uncertainty, so I perform sensitivity analysis with respect to this parameter. Intuitively, a standard deviation of $2 \%$ seems reasonable, since this ensures that the $95 \%$ confidence interval of the equity risk premium that the agent beliefs is possible is between $0 \%$ and $8 \%$ at age 20 . Compelling evidence that this is not overstating the degree of ambiguity can be derived from the financial literacy literature. When answering questions to establish financial literacy levels, Rooij van, Lusardi, and Alessie (2007) find that $22 \%$ of survey respondents answer that they do not know whether "considering a long time period, stocks, bonds, or savings accounts give the highest return". Furthermore 30\% gives the wrong answer and less than half give the correct answer. This at least indicates that it is a valid assumptions that a large fraction of agents is ambiguous about the equity premium, and in general about financial market parameters. Furthermore, even assuming that agents look up all previous stock market returns, the confidence interval about the equity premium would still be large. But since I have no means to determine the range of equity risk premium that agents deem possible, this section examines the influence of the initial ambiguity level on the results. The results from this section can also be viewed in light of that agents are different in their amount of ambiguity and how this influence the optimal fraction allocated to stocks and optimal participation levels. 


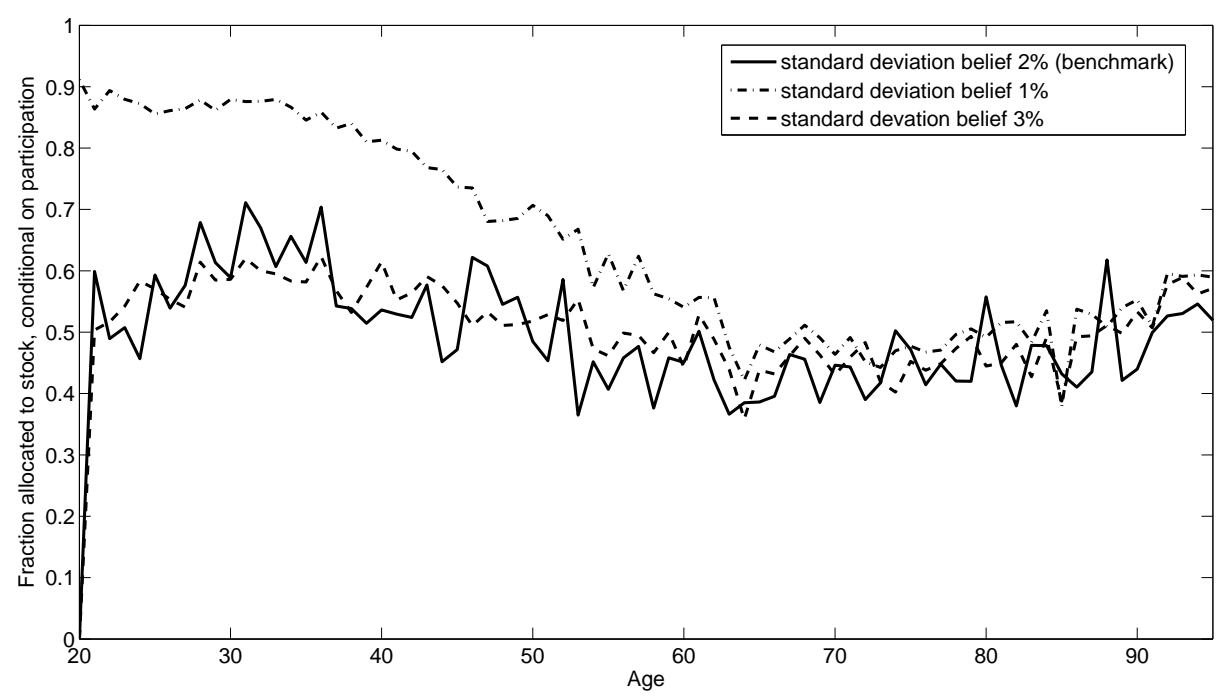

(a) Fraction allocated to stocks, conditional on participation

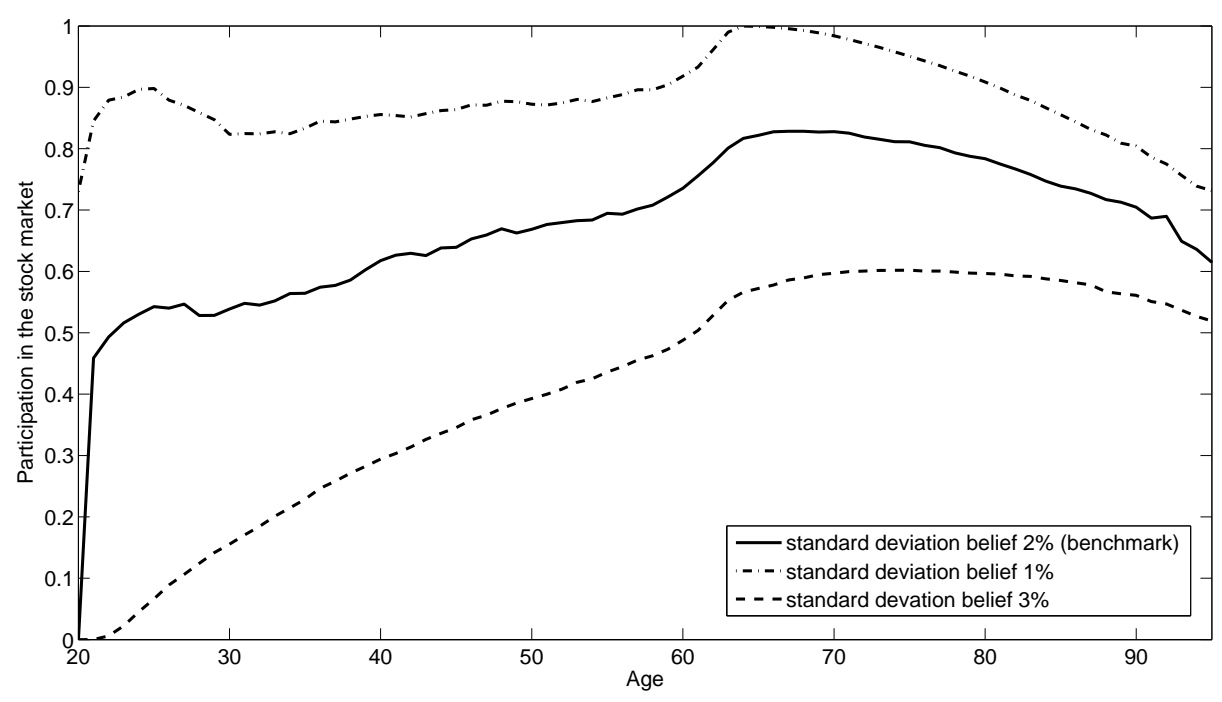

(b) Stock market participation

Figure 8: Stock market participation and conditional allocation to stocks for varying levels of initial ambiguity

I display the optimal conditional fraction of financial wealth allocated to stocks and optimal participation in the stock market for agents who are (1) ambiguous about the equity risk premium and learn about the parameters and who are (2) not ambiguous about the equity premium. The upper panel shows the fraction of financial wealth allocated to stocks, conditional on stock market participation. The lower panel shows the optimal participation level, which is unconditional on having positive financial wealth, and thus includes all the simulation paths. In case an agent has a near zero financial wealth level (below \$100), the optimal participation is set to zero. Agents learn about the equity risk premium. Maximin preferences are used and the parameters are as in the benchmark case, unless stated otherwise. 
Figure 8 displays the conditional allocation to equity and the participation in the stock market for varying levels of initial ambiguity. The optimal fraction allocated to stocks is approximately the same if the standard deviation of beliefs is $3 \%$ or $2 \%$. The reason is that only if agents have a worst case belief higher than zero, they participate in the stock market. Hence at age 20, no one participates. At age 21, agents have experienced stock return realizations the year before and update their beliefs. But the agent with a standard deviation of $3 \%$ needs a much larger positive update to have a worst case belief higher than $0 \%$ and participate, compared to an agent with a $2 \%$ standard deviation. So the participation levels are much lower, see Fig 8b, but once over the $0 \%$ hurdle (so conditional on participation), the fraction allocated is the same. The fraction of financial wealth allocated to stocks if agents have a standard deviation of beliefs of $1 \%$ is much higher at young ages, because the average worst case belief, conditional on having a positive worst case belief, is higher.

\subsection{Risk aversion}

In the benchmark case the risk aversion coefficient equals 5 and I will explore the effect of this assumption on the main findings, for which the results are presented in Figure 9. For the same reason as before, the optimal participation levels are only influenced by the risk aversion coefficient via the effect that risk aversion has on precautionary savings. So risk aversion influences the fraction of agents that have wealth higher than $\$ 100$ and thus affects the participation levels. As can be seen from Figure 9b, the participation levels change only slightly. The conditional stock allocations are plotted for a risk aversion coefficient of 2, 5, and 10 (Cocco, Gomes, and Maenhout (2005) use 10 for their benchmark case). The optimal fraction allocated to stocks, conditional on stock market participation, is sensitive to the risk aversion coefficient. There are two channels via which a higher risk aversion changes the optimal fraction. First, a higher risk aversion results in a decline in the optimal allocation to stocks directly since the agent is less risk tolerant and shifts the position to more riskless assets. In addition, precautionary savings increase if the risk aversion is higher to have a large buffer against labor market risk. This inflates the relative fraction of financial wealth to human capital and thus depresses the optimal fraction of financial wealth allocated to stocks. Both channels work in the same direction and for this reason the more risk averse the agent, the lower the optimal fraction invested in stocks. Note that for all levels of risk aversion the effect of ambiguity and learning on the stock market allocation is sizeable. 


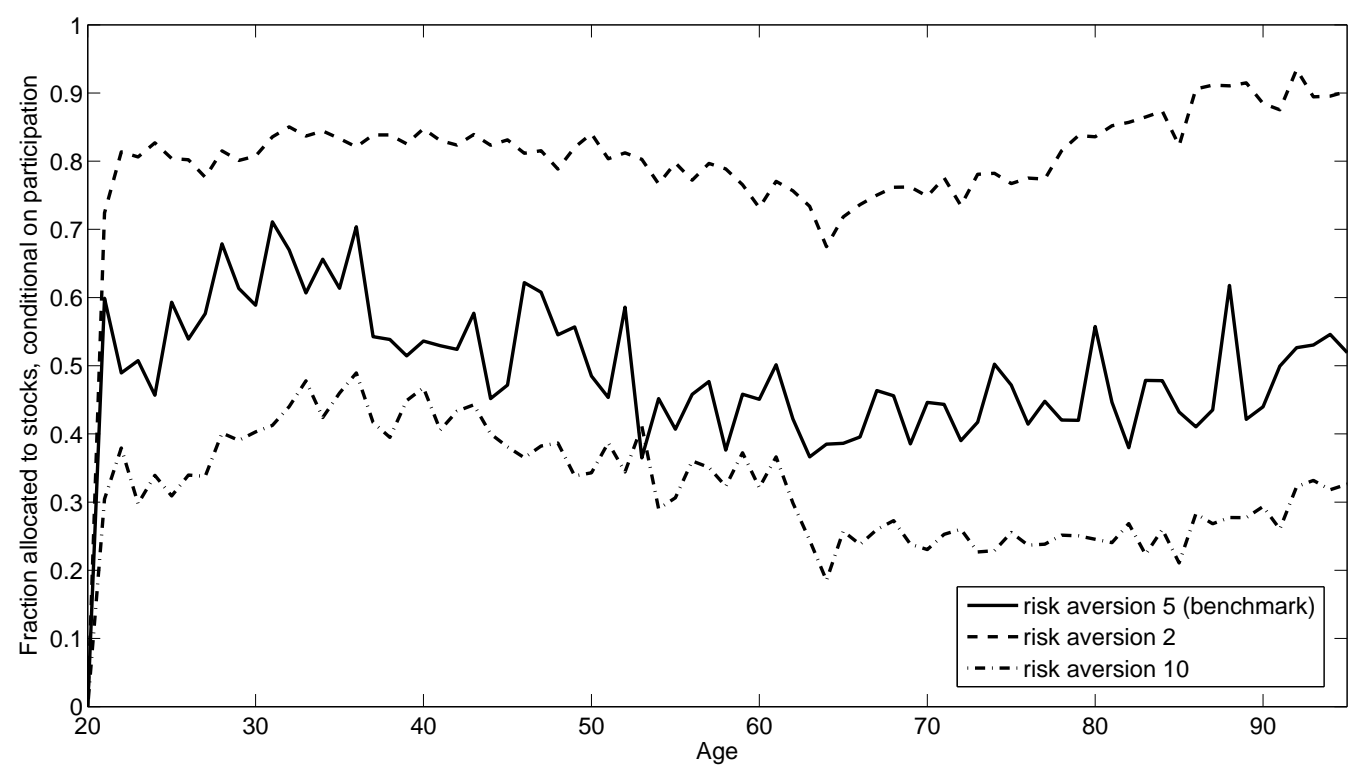

(a) Fraction allocated to stocks, conditional on participation

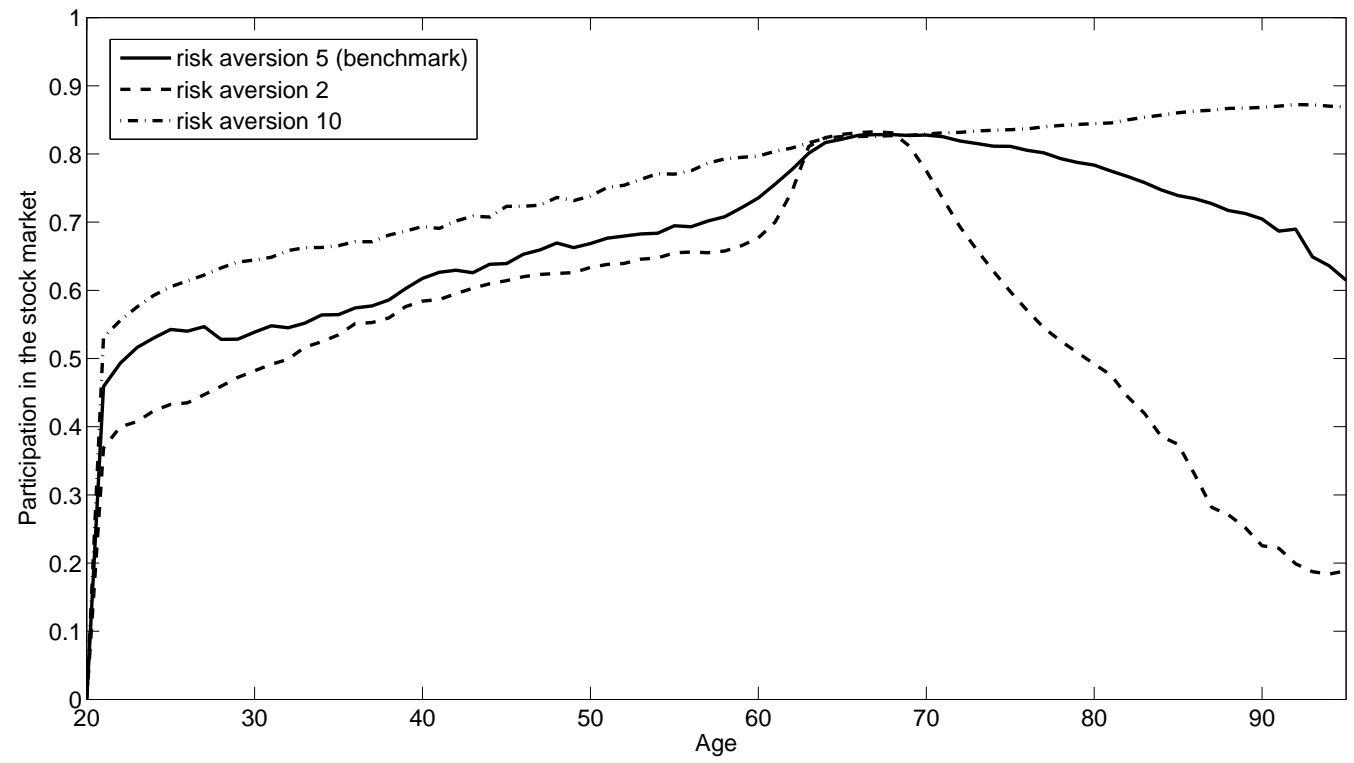

(b) Stock market participation

Figure 9: Stock market participation and conditional allocation to stocks for varying levels of risk aversion

I display the optimal conditional fraction of financial wealth allocated to stocks and optimal participation in the stock market for agents who are (1) ambiguous about the equity risk premium and learn about the parameters and who are (2) not ambiguous about the equity premium. The upper panel shows the fraction of financial wealth allocated to stocks, conditional on stock market participation. The lower panel shows the optimal participation level, which is unconditional on having positive financial wealth, and thus includes all the simulation paths. In case an agent has a near zero financial wealth level (below \$100), the optimal participation is set to zero. Agents learn about the equity risk premium. Maximin preferences are used and the parameters are as in the benchmark case, unless stated otherwise. 


\subsection{Labor income}

In the benchmark calibration I assume that the agent receives a stochastic income stream corresponding to a high school graduate. Cocco, Gomes, and Maenhout (2005) estimate the parameters for the income process for high school graduates, as well as individuals with no high school degree or with a college degree. Figure 10a presents the optimal fraction allocated to stocks, conditional on participation, for agents who have an income corresponding to (1) no high school degree, (2) a high school degree (benchmark), (3) a college degree, and (4) a high school degree but no labor income risk, while the other parameters are as in the benchmark case. The deviation in optimal stock allocation between a high school graduate and an agent with no high school degree stems from a combination of factors. The transitory income risk is higher for an agent with no high school degree, but the permanent income risk component is similar. This results in a decrease in the allocation to equity for an individual with no high school degree, since he faces more risk. On the one hand, the no high school graduate saves more due to the higher income risk, while on the other hand, he saves less since he has a higher replacement rate. So taking these effects together, an agent with no high school diploma has a slightly lower level invested in equity before retirement (after retirement there is no labor income risk). Similar reasoning holds for college graduates. On the one hand, the replacement rate is higher and the transitory income risk is lower, which induces less savings and thus a higher fraction of financial wealth allocated to equity. On the other hand, the permanent income risk is higher compared to an agent with a high school degree, which increases savings and a lower fraction allocated to stocks. Taking these three effects together results in a slightly higher allocation to stocks.

If an agent faces no labor income risk, he does not need to create a buffer against labor income shocks to smooth consumption. The only incentive to save is due to the replacement rate for retirement income, which is $68 \%$. So the agent starts savings from age 29 onwards to smooth consumption. In the graph it seems that the participation level is zero until age 36, but the optimal participation is actually about $0.1 \%$. The fraction of financial wealth to human capital rises until age 65, hence the optimal fraction allocated to stocks falls. As before, the optimal fraction increases after age 65 , since the financial wealth is depleted faster than human capital, due to the additional discount factor, survival probabilities. The effect of different labor income profiles on the optimal participation levels (Panel 10b) stems from the difference in savings motives, which induces a difference in the fraction of agents which has a wealth level above $\$ 100$. Overall, the results are robust for different stochastic labor income processes. So when taking into account the heterogeneity of agents with respect to labor income, the main finding hold: ambiguity about the equity risk premium decreases the amount allocated to stocks substantially. 


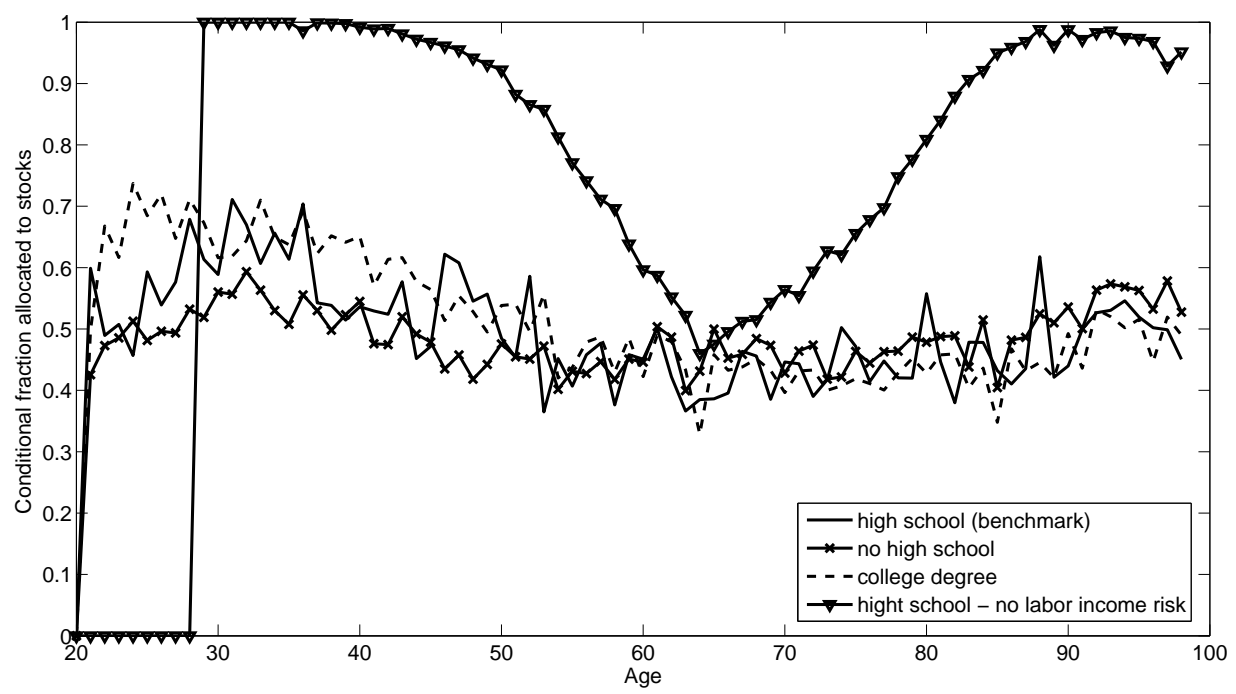

(a) Fraction allocated to stocks, conditional on participation

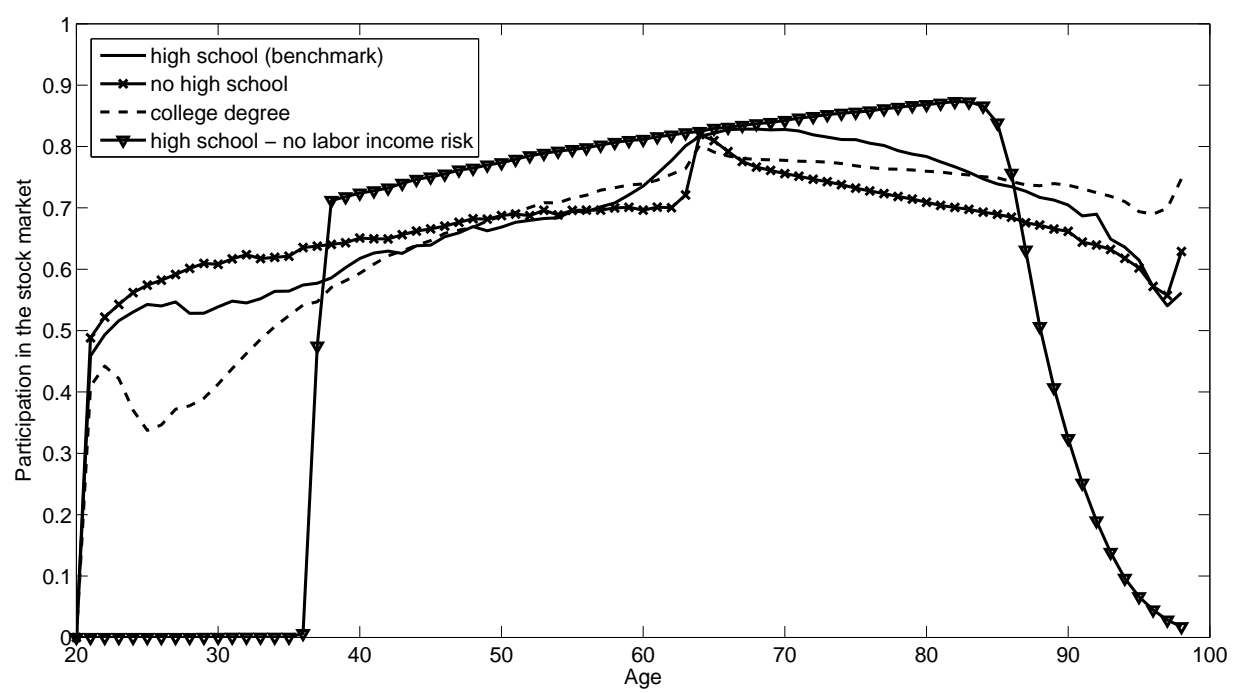

(b) Stock market participation

Figure 10: Stock market participation and conditional allocation to stocks for varying income levels.

I display the optimal conditional fraction of financial wealth allocated to stocks and optimal participation in the stock market for agents who are (1) ambiguous about the equity risk premium and learn about the parameters and who are (2) not ambiguous about the equity premium. The upper panel shows the fraction of financial wealth allocated to stocks, conditional on stock market participation. The lower panel shows the optimal participation level, which is unconditional on having positive financial wealth, and thus includes all the simulation paths. In case an agent has a near zero financial wealth level (below \$100), the optimal participation is set to zero. Agents learn about the equity risk premium. The benchmark case is the income process for a high school graduate (solid line). The dashed line is for a college graduate, the solid-crossed line for an individual with no high school degree, and the solid-triangle line for a deterministic income for a high school graduate. The parameters from Cocco, Gomes, and Maenhout (2005) are used. For college graduates: $\sigma_{u}^{2}=5.84 \%, \sigma_{\epsilon}^{2}=1.69 \%$ and the replacement rate is $94 \%$. For individuals with no high school degree: $\sigma_{u}^{2}=10.65 \%, \sigma_{\epsilon}^{2}=1.05 \%$ and the replacement rate is $89 \%$. The agent who faces no labor income risk, receives a similar deterministic income profile as an agent with a high school degree, except that the income is riskless. Maximin preferences are used and the parameters are as in the benchmark case, unless stated otherwise. 


\subsection{Can risk aversion substitute for ambiguity aversion?}

This paper shows that ambiguity about the equity risk premium can help solve the participation puzzle and explain the low fraction of financial wealth allocated to stocks over the life cycle. In this section I show that similar findings cannot be obtained by assuming higher risk aversion. The results are presented in Figure 11. First of all, risk aversion has almost no influence on optimal participation levels while ambiguity aversion has a large influence. The participation levels are only influenced by the worst case belief about the equity risk premium, and risk aversion has no influence on this. Higher risk aversion actually increases participation, since it increases precautionary savings. When risk aversion is 15 and agents are not ambiguity averse, the optimal fraction until age 65 is similar for the baseline risk aversion, $\gamma=5$, and ambiguity aversion. After age 65, the difference is substantial. Hence risk aversion does not act as a substitute for ambiguity aversion and I do not obtain the same results via increasing risk aversion compared to including ambiguity aversion. The reason is that, unlike ambiguity aversion, risk aversion increases the precautionary savings level to build up a buffer against labor income risk, which decreases the optimal fraction of financial wealth allocated to equity.

\section{Conclusion}

In this paper I develop a realistically calibrated life-cycle model with ambiguity aversion and learning to explore the impact of ambiguity about the equity risk premium on optimal portfolio allocations. I compare the model predictions with data from the Survey of Consumer Finances. Two important empirical facts are matched, the low participation levels in the stock market over the life cycle and the low fraction of financial wealth allocated to equity, conditional on participation. Furthermore, with this structural model I can disentangle age, cohort, and time effects in the equity allocation over the life cycle. Age effects arise due to ambiguity, learning, labor income, and a shortening horizon. I assume cohort effects can be identified via learning, because agents of the same age born in different years have seen different stock returns during their lifetime. Time effects are added to the model in the form of decreasing fees over the past decades. The empirical cross sectional allocation to stocks in 2007, 1998, and 1989 are compared to the predictions from the life-cycle model, which are calculated separately for 2007, 1998, and 1989, taking into account age, cohort, and time effects. The match is very close if cohort effects are assumed to be zero. Both the participation level and the conditional fraction in these three years differs maximally $25 \%$, comparing the match for all ages. The paper closest to this paper is Gomes and Michaelides (2005) who find an optimal fraction allocated to stocks of almost $100 \%$ when young, which is about $60 \%$ higher than the empirical fraction in stocks in 2007. 


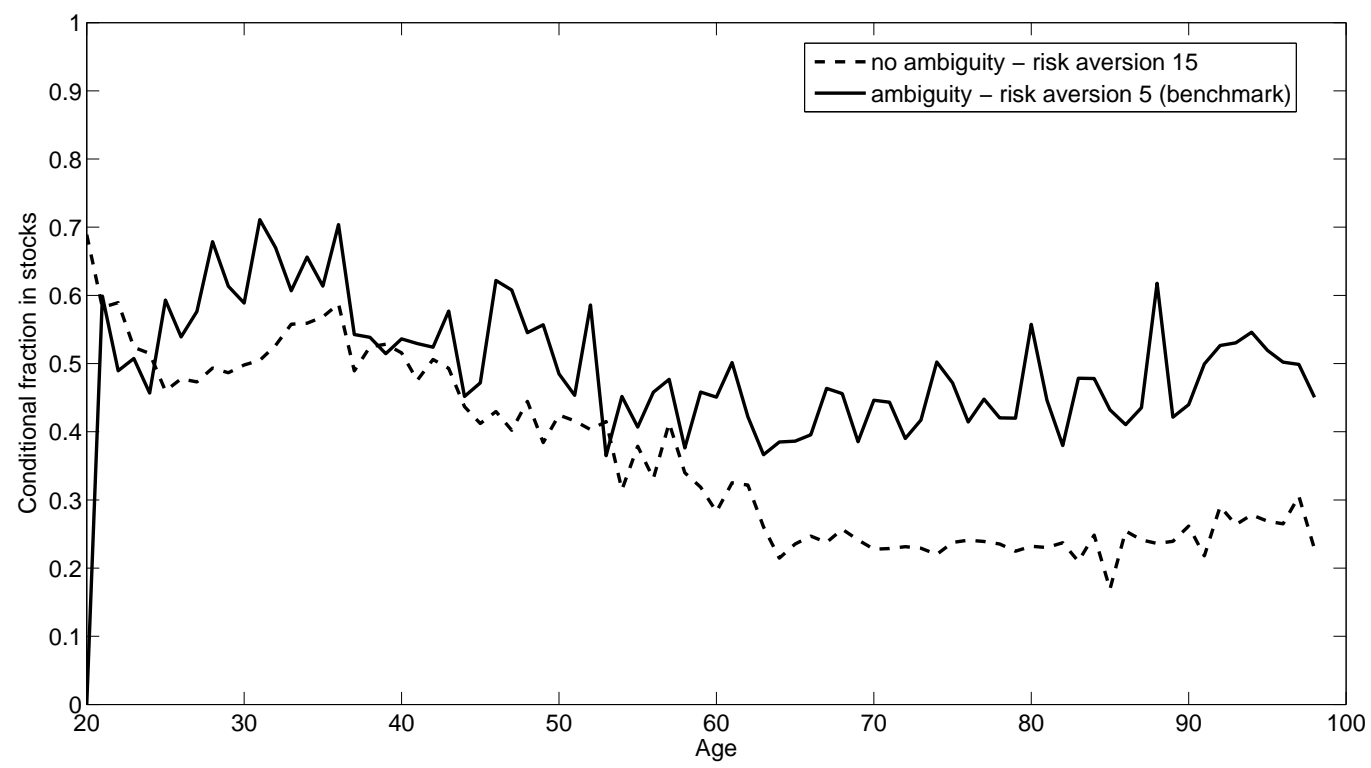

(a) Fraction allocated to stocks, conditional on participation

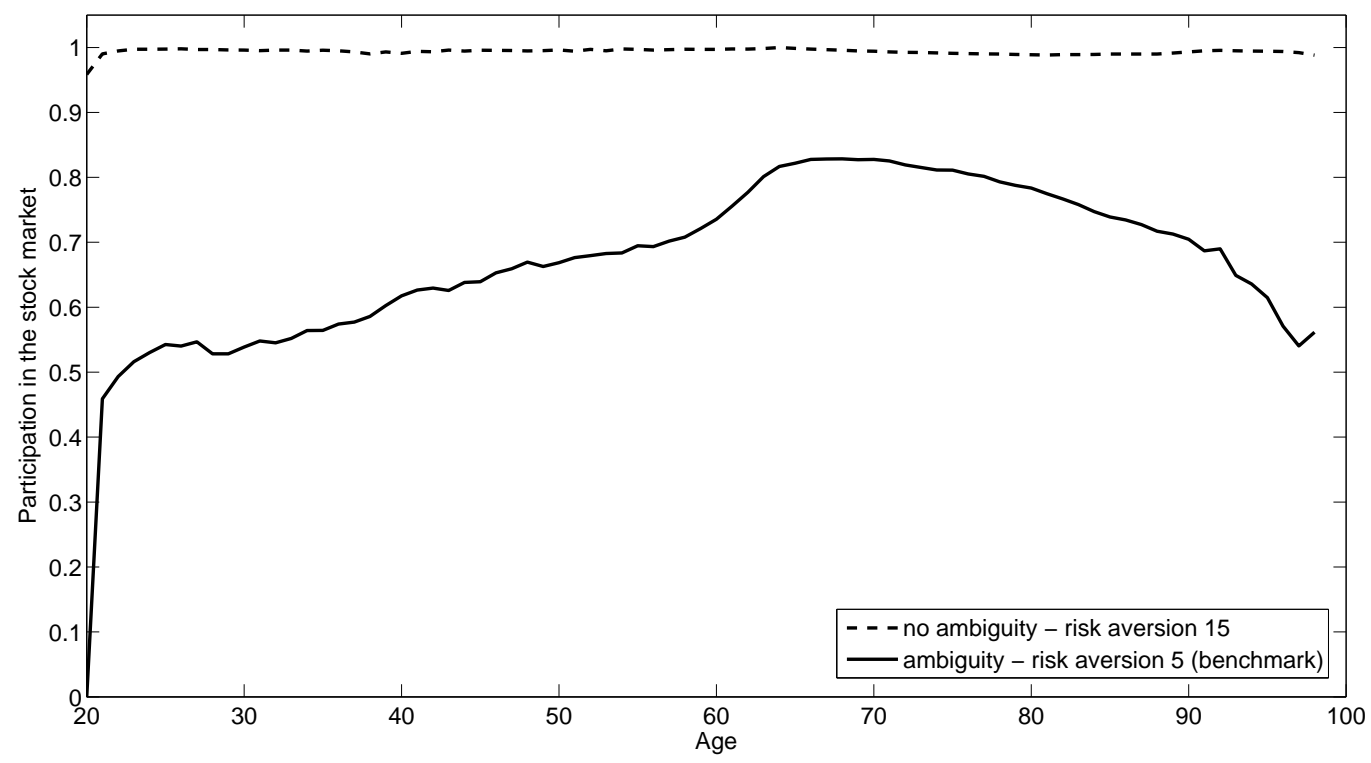

(b) Stock market participation

Figure 11: Allocation to stocks; can risk aversion substitute for ambiguity aversion

I display the optimal conditional fraction of financial wealth allocated to stocks and optimal participation in the stock market for agents who are (1) ambiguous about the equity risk premium and learn about the parameters and who are (2) not ambiguous about the equity premium. The upper panel shows the fraction of financial wealth allocated to stocks, conditional on stock market participation. The lower panel shows the optimal participation level, which is unconditional on having positive financial wealth, and thus includes all the simulation paths. In case an agent has a near zero financial wealth level (below \$100), the optimal participation is set to zero. Agents learn about the equity risk premium. Maximin preferences are used and the parameters are as in the benchmark case, unless stated otherwise. 


\section{References}

Abdellaoui, M., A. Baillon, L. Placido, and P. Wakker (2010): "The Rich Domain of Uncertainty: Source Functions and Their Experimental Implementation," forthcoming American Economic Review.

Ahn, D., S. Choi, D. Gale, And S. Kariv (2010): "Estimating Ambiguity Aversion in a Portfolio Choice Experiment,” Working paper, University of California, Berkeley.

Ameriks, J., And S. Zeldes (2004): "How Do Household Portfolio Shares Vary With Age?," Working paper.

Benzoni, L., P. Collin-Dufresne, and R. Goldstein (2007): "Portfolio Choice over the Life-Cycle when the Stock and Labor Market Are Cointegrated," The Journal of Finance, 62(5), 2123-2167.

Bossaerts, P., P. Ghirardato, S. Guarnaschelli, and W. Zame (2010): "Ambiguity in Asset Markets: Theory and Experiment," Review of Financial Studies, 23(4), 1325-1359.

Boyle, P., L. Garlappi, R. Uppal, and T. Wang (2009): "Keynes Meets Markowitz: The Tradeoff Between Familiarity and Diversification,” CEPR Discussion paper, No. 7687.

Brandt, M., A. Goyal, P. Santa-Clara, and J. Stroud (2005): "A Simulation Approach to Dynamic Portfolio Choice with an Application to Learning About Return Predictability," Review of Financial Studies, 18(3), 831-873.

Buraschi, A., AND A. Jiltsov (2006): "Model Uncertainty and Option Markets with Heterogeneous Beliefs," Journal of Finance, 61(6), 2841-2897.

Campanale, C. (2009): "Learning, Ambiguity, and Life-Cycle Portfolio Allocation," forthcoming Review of Economic Dynamics.

CAO, H., T. WAng, And H. Zhang (2005): "Model Uncertainty, Limited Market Participation, and Asset Prices," Review of Financial Studies, 18(4), 1219-1251.

Carroll, C. (2006): “The Method of Endogenous Gridpoints for Solving Dynamic Stochastic Optimization Problems," Economics Letters, 91(3), 312-320.

Chen, H., N. Ju, And J. Miao (2009): "Dynamic Asset Allocation with Ambiguous Return Predictability," Working paper, MIT Sloan School of Management. 
Chen, Z., And L. Epstein (2002): “Ambiguity, Risk, and Asset Returns in Continuous Time," Econometrica, 70(4), 1403-1443.

Cocco, J. (2005): "Portfolio Choice in the Presence of Housing," Review of Financial Studies, $18(2), 535-567$.

Cocco, J., F. Gomes, and P. Maenhout (2005): "Consumption and Portfolio Choice over the Life Cycle," Review of Financial Studies, 18(2), 491-533.

Collard, F., S. Mukerji, K. Sheppard, and J.-M. Tallon (2009): “Ambiguity and the Historical Equity Premium,” Working paper, Oxford University.

Cvitanic, J., A. Lazrak, L. Martellini, and F. Zapatero (2006): "Dynamic Portfolio Choice with Parameter Uncertainty and the Economic Value of Analysts' Recomendations," Review of Financial Studies, 19(4), 1113-1156.

Dow, J., S. Ribeiro, And C. Werlang (1992): "Uncertainty Aversion, Risk Aversion, and the Optimal Choice of Portfolio," Econometrica, 60(1), 197-204.

Easley, D., And M. O’Hara (2009): “Ambiguity and Nonparticipation: The Role of Regulation," The Review of Financial Studies, 22(5), 1817-1843.

EASLEY, D., AND M. O’HARA (2010): “Liquidity and Valuation in an Unceretain World,” Journal of Financial Economics, 97(1), 1-11.

EllsberG, D. (1961): "Risk, Ambiguity, and the Savage Axioms," Quaterly Journal of Economics, 75(4), 643-669.

Epstein, L., J. NoOR, And A. SANDroni (2010): “Non-Baysian Learning,” The B.E. Journal of Theoretical Economics, 10(1).

EPSTEIn, L., AND M. SCHNEIDER (2003): “Recursive Multiple-priors," Journal of Economic Theory, 113, 1-31.

(2007): “Learning under Ambiguity," Review of Economic Studies, 74(4), 1275-1303.

(2008): “Ambiguity, Information Quality, and Asset Pricing," Journal of Finance, 63(1), $197-228$.

(2010): “Ambiguity and Asset Markets,” Working paper, Boston University.

FAria, G., J. Correira-DA-Silva, And C. Ribeiro (2009): "Dynamic Consumption and Portfolio Choice with Ambiguity about Stochastic Volatility," FEP Working paper, N. 348. 
Gagliardini, P., P. Porchia, and F. Trojani (2009): "Ambiguity Aversion and the Term Structure of Interest Rates," The Review of Financial Studies, 22(10), 4157-4188.

GARLAPPI, L., R. UPPAL, AND T. WANG (2007): "Portfolio Selection with Parameter and Model Uncertainty: A Multi-Prior Approach," Review of Financial Studies, 20(1), 41-81.

GilboA, I., AND D. SchmeIdler (1989): "Maximin Expected Utility with Non-unique Prior," Journal of Mathematical Economics, 18, 141-153.

Gollier, C. (2009): "Portfolio Choices and Asset Prices: The Comparative Statics of Ambiguity Aversion," Working paper, Toulouse School of Economics.

Gomes, F., And A. Michaelides (2005): “Optimal Life Cycle Asset Allocation: Understanding the Empirical Evidence," Journal of Finance, 60(2), 869-904.

Guidolin, M., And F. Rinaldi (2010): "Amgiguity in Asset Pricing and Portfolio Choice: A Review of the Literature," Federal Reserve Bank of St. Louis working paper series No. 2010028A.

Hanany, E., And P. Klibanoff (2009): “Updating Ambiguity Averse Preferences,” The B.E. Journal of Theoretical Economics, 9(1), 1-51.

HAnsen, L., And T. SARgent (2001): "Robust Control and Model Uncertainty," American Economic Review, 91(2), 60-66.

HAYASHI, T., AND R. WADA (2010): "Choice with Imprecise Information: An Experimental Approach," Theory and Decision, 69(3), 355-373.

Heaton, J., And D. LuCAs (2000): "Portfolio Choice in the Presence of Background Risk," The Economic Journal, 110(1), 1-26.

ILLEDITSCH, P. (2010): “Ambiguous Information, Porfolio Inertia, and Excess Volatility,” Working paper, The Wharton School.

JU, N., AND J. MiaO (2010): “Ambiguity, Learning, and Asset Returns,” Working paper, Hong Kong University of Science and Technology.

Klibanoff, P., M. Marinacci, And S. MukerJi (2005): “A Smooth Model of Decision Making under Ambiguity," Econometrica, 73(6), 1849-1892.

- (2009): "Recursive Smooth Ambiguity Preferences," Journal of Economic Theory, 144(3), 930-976. 
Knight, F. (1921): Risk, Uncertainty, and Profit. Hart, Schaffner, and Marx Prize Essays, no. 31. Boston and New York: Houghton Mifflin.

Koijen, R., T. NiJman, And B. Werker (2010): "When Can Life Cycle Investors Benefit from Time-Varying Bond Risk Premia?," Review of Financial Studies, 23(2), 741-780.

Leippold, M., F. Trojani, and P. VAnini (2008): "Learning and Asset Prices Under Ambiguous Information," The Review of Financial Studies, 21(6), 2565-2597.

LinnainmaA, J. (2007): “Learning and Stock Market Participation,” Working paper, University of Chicago.

LIU, H. (2010): "Dynamic Portfolio Choice under Ambiguity and Regime Switching Mean Returns," Working paper, University of Manchester.

Maenhout, P. (2004): "Robust Portfolio Rules and Asset Pricing," Review of Financial Studies, 17(4), 951-983.

Malmendier, U., And S. NAGel (2010): “Depression Babies: Do Macroeconomic Experiences Affect Risk-Taking?," forthoming, Quarterly Journal of Economics.

Mele, A., And F. SAngiorgi (2009): "Uncertainty, Information Acquisition and Price Swings in Asset Markets," Working paper, London School of Economics.

Merton, R. (1969): "Lifetime Portfolio Selection under Uncertainty: The Continuous-time Case," Review of Economics and Statistics, 51(3), 247-257.

MiAO, J. (2009): “Ambiguity, Risk and Portfolio Choice under Incomplete Information,” Annals of Economics and Finance, 10(2), 257-279.

PAiElla, M. (2001): "Limited Financial Market Participation: A Transaction Cost-Based Explanation," Working paper, Bank of Italy.

PASTOR, L., AND P. Veronesi (2009): "Learning in Financial Markets," Annual Review of Financial Economics, 1, 361-381.

Polkovnichenko, V. (2007): "Life Cycle Portfolio Choice with Additive Habit Formation Preferences and Uninsurable Income Risk," Review of Financial Studies, 20(1), 83-124.

Poterba, J., And A. SAmwick (1997): "Household Portfolio Allocation over the Life Cycle," NBER Working Paper 6185. 
Rooij VAn, M., A. Lusardi, And R. Alessie (2007): "Financial Literacy and Stock Market Participation," NBER Working paper No. 13565.

SAmuelson, P. (1969): "Lifetime Portfolio Selection by Dynamic Stochastic Programming," Review of Economics and Statistics, 51(3), 239-246.

VICEIRA, L. (2001): "Optimal Portfolio Choice for Long-horizon Investors with Non-tradable Labor Income,” Journal of Finance, 56(2), 433-470.

Vissing-Jorgenson, A. (2002): "Towards an Explanation of Household Portfolio Choice Heterogeneity: Nonfinancial Income and Participation Cost Structures,” NBER Working paper No. 8884.

Williams, C. (2009): “Asymmetric Responses to Good and Bad News: An Empirical Case for Ambiguity," Working paper, University of Michigan.

YaO, R., And H. Zhang (2005): “Optimal Consumption and Portfolio Choice with Risky Housing and Borrowing Constraints," Review of Financial Studies, 18(1), 197-239.

\section{A Numerical method to solve the life-cycle model with ambi- guity aversion}

\section{A.1 Short summary life-cycle problem with smooth ambiguity preferences}

The investor solves the following Bellman equation at time $t \neq T$

$$
\begin{aligned}
& V_{t}\left(W_{t}, Y_{t}, \lambda_{t}^{B}\right)=\max _{w_{t}, C_{t}} u\left(C_{t}\right)+ \\
& \beta p_{t+1} \phi^{-1}\left(\int_{\Lambda_{t}}\left\{\phi\left(\mathbb{E}_{t}^{\lambda}\left\{V_{t+1}\left(W_{t+1}, Y_{t+1}, \lambda_{t+1}^{B}\right)\right\}\right)\right\}\right),
\end{aligned}
$$

where $C_{t}$ is consumption. Agents employ an uncertainty aversion function $\phi$. The exogenous state variables are income $\left(Y_{t}\right)$ and the mean of the belief about the expected equity premium $\left(\lambda_{t}^{B}\right)$. Wealth $\left(W_{t}\right)$ is an endogenous state variable. At time $T$ the investor consumes all wealth, hence the value function equals:

$$
V_{T}\left(W_{T}, Y_{T}, \lambda_{T}^{B}\right)=u\left(W_{T}\right)
$$

The dynamics of financial wealth are given by

$$
W_{t+1}=\left(W_{t}-C_{t}+Y_{t}\right)\left(1+R^{f}+w_{t}\left(R_{t+1}-R^{f}\right)\right)
$$


I assume a constant relative risk aversion utility function (CRRA) and a constant absolute ambiguity aversion utility function (CAAA):

$$
\begin{array}{r}
u\left(C_{t}\right)=\frac{C_{t}^{1-\gamma}}{1-\gamma} \\
\phi(x)=-\exp (-\alpha x) .
\end{array}
$$

The individual faces a number of constraints on the consumption and investment decisions. First, I assume that the agent faces borrowing and short-sales constraints

$$
w_{t} \geq 0 \text { and } \iota^{\prime} w_{t} \leq 1
$$

Second, I impose that the investor is liquidity constrained

$$
C_{t} \leq W_{t}
$$

which implies that the individual cannot borrow against future income to increase consumption today.

The timing is as follows, first an individual receives his income, after which he consumes. Subsequently he invests the remaining wealth, either in equity or a riskless asset.

\section{A.2 Beliefs about the mean return on equity}

The agent has beliefs about the equity risk premium and the mean of his beliefs is $\lambda_{t}^{B}$ and the standard deviation of his belief about the equity risk premium is $\sigma_{t}^{B}$. I limit the set of beliefs that the agent thinks are viable to be bounded by a $95 \%$ confidence interval. Hence the beliefs on the possible mean equity return lies in the range of $\left[\lambda_{t}^{B}-2 \sigma_{t}^{B} ; \lambda_{t}^{B}+2 \sigma_{t}^{B}\right]$. I make a grid for the possible mean stock returns by dividing the confidence interval in $K$ equal probability areas. Subsequently I calculate the average of the outer bound of each area separately and the probability that the agent attaches to this expected stock return is $1 / K$.

\section{A.3 The first order conditions - smooth recursive preferences}

In period $T$ the optimal policies are easily determined. Namely the agent consumes the entire wealth level and no optimal investment strategy need to be made. In all other time periods optimal decisions on consumption and investment are calculated by setting the first order conditions equal to zero. The optimization problem is solved via dynamic programming and I proceed backwards. 
I define the portfolio return as:

$$
R_{t+1}^{P}=1+R^{f}+\left(R_{t+1}-R^{f}\right) w_{t} .
$$

Furthermore I denote the wealth level after income and consumption as:

$$
A_{t}=W_{t}+Y_{t}-C_{t}
$$

Consider that the agent is at time $t$, after having consumed $C_{t}$, and he/she has to choose $w_{t}$ so as to maximize the bellman equation. The first-order condition with respect to $w_{t}$ for this problem is.

$$
\begin{aligned}
\frac{\partial V_{t}}{\partial w_{t}}= & \beta p_{t+1}\left(\frac{1}{\phi^{\prime}\left(\phi^{-1}(.)\right)}\right) \\
& \int_{\Lambda_{t}}\left\{\phi^{\prime}\left(\mathbb{E}_{t}^{\lambda}\left\{V_{t+1}\left(W_{t+1}\right)\right\}\right) \mathbb{E}_{t}^{\lambda}\left\{\frac{\partial V_{t+1}}{\partial W_{t+1}}\left(W_{t}+Y_{t}-C_{t}\right)\left(R_{t+1}-R^{f}\right)\right\}\right\},
\end{aligned}
$$

where

$$
=\int_{\Lambda_{t}}\left\{\phi\left(\mathbb{E}_{t}^{\lambda}\left\{V_{t+1}\left(W_{t+1}\right)\right\}\right)\right\} .
$$

So similar but written differently:

$$
\begin{aligned}
\frac{\partial V_{t}}{\partial w_{t}}= & \beta p_{t+1}\left(\phi^{-1}\right)^{\prime}\left(\int_{\Lambda_{t}}\left\{\phi\left(\mathbb{E}_{t}^{\lambda}\left\{V_{t+1}\left(W_{t+1}\right)\right\}\right)\right\}\right) \\
& \int_{\Lambda_{t}}\left\{\phi^{\prime}\left(\mathbb{E}_{t}^{\lambda}\left\{V_{t+1}\left(W_{t+1}\right)\right\}\right) \mathbb{E}_{t}^{\lambda}\left\{\frac{\partial V_{t+1}}{\partial W_{t+1}}\left(W_{t}+Y_{t}-C_{t}\right)\left(R_{t+1}-R^{f}\right)\right\}\right\} .
\end{aligned}
$$

The first order condition with respect to $C_{t}$ equals:

$$
\begin{aligned}
\frac{\partial V_{t}}{\partial C_{t}}= & C_{t}^{-\gamma}-\beta p_{t+1}\left(\phi^{-1}\right)^{\prime}\left(\int_{\Lambda_{t}}\left\{\phi\left(\mathbb{E}_{t}^{\lambda}\left\{V_{t+1}\left(W_{t+1}\right)\right\}\right)\right\}\right) \\
& \int_{\Lambda_{t}}\left\{\phi^{\prime}\left(\mathbb{E}_{t}^{\lambda}\left\{V_{t+1}\left(W_{t+1}\right)\right\}\right) \mathbb{E}_{t}^{\lambda}\left\{\frac{\partial V_{t+1}}{\partial W_{t+1}}\left(1+R^{f}+w_{t}\left(R_{t+1}-R^{f}\right)\right)\right\}\right\} .
\end{aligned}
$$

Next I take the total derivative with respect to $W_{t}$

$$
\begin{aligned}
\frac{\partial V_{t}}{\partial W_{t}}= & \beta p_{t+1}\left(\phi^{-1}\right)^{\prime}\left(\int_{\Lambda_{t}}\left\{\phi\left(\mathbb{E}_{t}^{\lambda}\left\{V_{t+1}\left(W_{t+1}\right)\right\}\right)\right\}\right) \\
& \int_{\Lambda_{t}}\left\{\phi^{\prime}\left(\mathbb{E}_{t}^{\lambda}\left\{V_{t+1}\left(W_{t+1}\right)\right\}\right) \mathbb{E}_{t}^{\lambda}\left\{\frac{\partial V_{t+1}}{\partial W_{t+1}}\left(1+R^{f}+w_{t}\left(R_{t+1}-R^{f}\right)\right)\right\}\right\} .
\end{aligned}
$$


Substitute equation (36) into equation (37)

$$
\begin{aligned}
\frac{\partial V_{t}}{\partial W_{t}} & =C_{t}^{-\gamma} \\
\frac{\partial V_{t+1}}{\partial W_{t+1}} & =C_{t+1}^{-\gamma} .
\end{aligned}
$$

Substitute equation (39) into equation (35) to obtain the first order condition for the asset allocation:

$$
\begin{aligned}
\frac{\partial V_{t}}{\partial w_{t}}= & \beta p_{t+1}\left(\phi^{-1}\right)^{\prime}\left(\int_{\Lambda_{t}}\left\{\phi\left(\mathbb{E}_{t}^{\lambda}\left\{V_{t+1}\left(W_{t+1}\right)\right\}\right)\right\}\right) \\
& \int_{\Lambda_{t}}\left\{\phi^{\prime}\left(\mathbb{E}_{t}^{\lambda}\left\{V_{t+1}\left(W_{t+1}\right)\right\}\right) \mathbb{E}_{t}^{\lambda}\left\{C_{t+1}^{*-\gamma}\left(R_{t+1}-R^{f}\right)\right\}\right\} .
\end{aligned}
$$

To solve for the optimal consumption, substitute equation (39) into equation (36) to get the following first order condition

$$
\begin{aligned}
C_{t}^{-\gamma}= & \beta p_{t+1}\left(\phi^{-1}\right)^{\prime}\left(\int_{\Lambda_{t}}\left\{\phi\left(\mathbb{E}_{t}^{\lambda}\left\{V_{t+1}\left(W_{t+1}\right)\right\}\right)\right\}\right) \\
& \int_{\Lambda_{t}}\left\{\phi^{\prime}\left(\mathbb{E}_{t}^{\lambda}\left\{V_{t+1}\left(W_{t+1}\right)\right\}\right) \mathbb{E}_{t}^{\lambda}\left\{C_{t+1}^{*-\gamma}\left(1+R^{f}+w_{t}\left(R_{t+1}-R^{f}\right)\right)\right\}\right\} .
\end{aligned}
$$

In addition I use:

$$
\begin{aligned}
\phi^{-1} & =-\frac{1}{\alpha} \ln (-y), \\
\left(\phi^{-1}\right)^{\prime} & =\frac{-1}{\alpha y}, \\
\phi^{\prime} & =\alpha \exp (-\alpha x) .
\end{aligned}
$$

\section{A.4 Optimization procedure for the optimal asset weights - smooth recur- sive preferences}

Due to the complexity of the model it cannot be solved analytically. Instead I use numerical optimization techniques to solve the problem. In this section I will explain this procedure, which combines the methods of Brandt, Goyal, Santa-Clara, and Stroud (2005) and Carroll (2006), with several extensions added by Koijen, Nijman, and Werker (2010). Brandt, Goyal, Santa-Clara, and Stroud (2005) propose to approximate the conditional expectations by regressing the realizations of the Euler conditions on a polynomial expansion of the state variables. All state variables except for wealth can be simulated, since only financial wealth is endogenous. To deal with this endogenous state variable I follow Carroll (2006) who proposes a grid for wealth after consumption, $A_{t}$, instead 
of a grid for wealth, $W_{t}$. This choice allows us to solve the Euler conditions analytically instead of numerically and I form a M-dimensional grid for wealth after consumption. Additionally, I use extensions by Koijen, Nijman, and Werker (2010) to increase the optimization speed. I construct $\mathrm{H}$ test portfolios and let the weight invested in the risky asset run from $0 \%$ to $+100 \%$, with steps of $5 \%$, hence $\mathrm{H}$ is 21 . The return on the test portfolios is defined as $R_{t+1}^{\text {test }}$. Furthermore we simulate $\mathrm{N}$ trajectories of $\mathrm{T}$ periods for every state variable

The problem is solved via backwards recursion and to solve the optimal policies at time $t$, I have available the endogenous wealth grid at time $t+1$ and the optimal consumption at time $t+1$.

First I need to determine the two conditional expectations in equation (40):

$$
\begin{array}{r}
\mathbb{E}_{t}^{\lambda}\left\{C_{t+1}^{*-\gamma}\left(R_{t+1}-R^{f}\right)\right\} \\
\mathbb{E}_{t}^{\lambda}\left\{V_{t+1}\left(W_{t+1}\right)\right\}
\end{array}
$$

The conditional expectation in equation (45) is straightforward to calculate. I have the optimal consumption at period $t+1$, since I solve via backwards recursion. To obtain $C_{t+1}^{*}$ I interpolate linearly to make sure it is the optimal consumption next period that belongs to the grid point for after consumption wealth at time $\mathrm{t}, A_{t}$. I approximate the conditional expectation with a polynomial expansions in the state variables:

$$
\mathbb{E}_{t}^{\lambda}\left\{C_{t+1}^{*-\gamma}\left(R_{t+1}-R^{f}\right)\right\} \simeq \rho f\left(Y_{t}, \lambda_{t}^{B}\right)
$$

This is done for each simulation path and MxK grid points.

The second conditional expectation (46) requires some more steps. The goal is to determine the realizations of $V_{t+1}$ regress these on the state variables at time $t$ to obtain the conditional expectation. The value function at time $t+1$ is

$$
V_{t+1}=u\left(C_{t+1}^{*}\right)+\beta p_{t+1} \phi^{-1}\left(\int_{\Lambda_{t+1}}\left\{\phi\left(\mathbb{E}_{t+1}^{\lambda_{t+1}}\left\{V_{t+2}\left(W_{t+2}, w_{t+2}^{*}\right)\right\}\right)\right\}\right) .
$$

A star $*$ denotes the optimal policies which I already calculated. Again I use interpolation to obtain the intermediate consumption levels. Furthermore I need $V_{t+2}$ which belongs to the grid points for after consumption wealth at time $t$, and not the grid point at time $t+1$, so similarly I use interpolation. The value of the Bellman equation at time $t+2, V_{t+2}$, is saved at the end of every time period since I solve via backwards recursion. As before, to obtain $\mathbb{E}_{t+1}^{\lambda_{t+1}}\left(V_{t+2}\right)$ I regress $V_{t+2}$ on the state variables at time $t+1$. Note that when determining the optimal policies at time $T-1$, $V_{T+1}=0$ and $V_{T}=u\left(W_{T}\right)$.

Agents are uncertain about the equity risk premium hence the optimization problem requires 
several additional steps. Namely in this setup $\mathbb{E}_{t+1}\left(V_{t+2}\right)$ is random. The beliefs are distributed in such a way that there is a $1 / K$ probability that the true equity risk premium lies between two of the grid points for the equity premium. Hence to calculate $\left(\int_{\Lambda_{t+1}}\left\{\phi\left(\mathbb{E}_{t+1}^{\lambda_{t+1}}\left\{V_{t+2}\left(W_{t+2}, w_{t+2}^{*}\right)\right\}\right)\right\}\right)$, I need to take the (weighted) average of $\phi E_{t+1}^{\lambda_{t+1}}\left(V_{t+2}\right)$ over the grid of beliefs about the equity risk premium. Next I plug all these calculated numbers is equation (48). Following Brandt, Goyal, Santa-Clara, and Stroud (2005) I regress the realizations of the Euler condition $\left(V_{t+1}\left(W_{t+1}\right)\right)$ on the state variables to obtain the conditional expectation, $\mathbb{E}_{t}^{\lambda}\left\{V_{t+1}\left(W_{t+1}\right)\right\}$.

Recall the first order condition for the optimal asset weights:

$$
\begin{aligned}
\frac{\partial V_{t}}{\partial w_{t}}= & \beta p_{t+1}\left(\phi^{-1}\right)^{\prime}\left(\int_{\Lambda_{t}}\left\{\phi\left(\underline{\mathbb{E}_{t}^{\lambda}\left\{V_{t+1}\left(W_{t+1}\right)\right\}}\right)\right\}\right) \\
& \int_{\Lambda_{t}}\left\{\phi^{\prime}\left(\underline{\mathbb{E}_{t}^{\lambda}\left\{V_{t+1}\left(W_{t+1}\right)\right\}}\right) \underline{\mathbb{E}_{t}^{\lambda}\left\{C_{t+1}^{*-\gamma}\left(R_{t+1}-R^{f}\right)\right\}}\right\} .
\end{aligned}
$$

Note that the steps to calculate the underlined parts of the equations are already explained. $\mathbb{E}_{t}^{\lambda}\left\{V_{t+1}\left(W_{t+1}\right)\right\}$ is a NxMxKxH matrix and I plug these numbers in the ambiguity aversion function $\phi$. Subsequently the weighted average is taken and the K-dimension falls out. Analogue the entire equation (49) is calculated.

Following Koijen, Nijman, and Werker (2010) the optimal asset weights are determined in two steps. First I approximate the conditional expectation with a polynomial state variables.

$$
\begin{aligned}
& \beta p_{t+1}\left(\phi^{-1}\right)^{\prime}\left(\int_{\Lambda_{t}}\left\{\phi\left(\mathbb{E}_{t}^{\lambda}\left\{V_{t+1}\left(W_{t+1}\right)\right\}\right)\right\}\right) \int_{\Lambda_{t}}\left\{\phi^{\prime}\left(\mathbb{E}_{t}^{\lambda}\left\{V_{t+1}\left(W_{t+1}\right)\right\}\right) \mathbb{E}_{t}^{\lambda}\left\{C_{t+1}^{*-\gamma}\left(R_{t+1}-R^{f}\right)\right\}\right\} \\
& =\rho^{\prime} f\left(Y_{t}, \lambda_{t}^{B}\right)
\end{aligned}
$$

Subsequently the projection coefficients, $\rho$, are parameterized in the asset weights. I let the projection coefficients depend on the "test" asset weights $(x)$, which I previously made a H-dimensional grid over. Hence for every simulated path I calculate $\mathrm{H}$ test portfolio returns. Since $\rho$ is a smooth function of the asset weights I can obtain:

$$
\rho(x) \simeq \Psi g(x)
$$

where $\mathrm{g}(\mathrm{x})$ is a polynomial expansion in the asset weights. This implies that the conditional expectation of the Euler condition is approximated via

$$
\begin{aligned}
& \beta p_{t+1}\left(\phi^{-1}\right)^{\prime}\left(\int_{\Lambda_{t}}\left\{\phi\left(\mathbb{E}_{t}^{\lambda}\left\{V_{t+1}\left(W_{t+1}\right)\right\}\right)\right\}\right) \int_{\Lambda_{t}}\left\{\phi^{\prime}\left(\mathbb{E}_{t}^{\lambda}\left\{V_{t+1}\left(W_{t+1}\right)\right\}\right) \mathbb{E}_{t}^{\lambda}\left\{C_{t+1}^{*-\gamma}\left(R_{t+1}-R^{f}\right)\right\}\right\} \\
& =g(x)^{\prime} \Psi^{\prime} f\left(Y_{t}, \lambda_{t}^{B}\right) .
\end{aligned}
$$


A polynomial expansion of order one is sufficient for this life-cycle problem, hence for every simulation path I solve:

$$
0=\left(\begin{array}{c}
1 \\
w^{*}
\end{array}\right) \Psi^{\prime} f\left(Y_{t}, \lambda_{t}^{B}, \sigma_{t}^{B}\right),
$$

which can be solved analytically, taking into account the portfolio constraints.

\section{A.5 Optimization procedure for the optimal consumption - smooth recur- sive preferences}

The derivative of the value function with respect to $C_{t}$ is equal to:

$$
\begin{aligned}
C_{t}^{-\gamma}= & \beta p_{t+1}\left(\phi^{-1}\right)^{\prime}\left(\int_{\Lambda_{t}}\left\{\phi\left(\mathbb{E}_{t}^{\lambda}\left\{V_{t+1}\left(W_{t+1}\right)\right\}\right)\right\}\right) \\
& \int_{\Lambda_{t}}\left\{\phi^{\prime}\left(\mathbb{E}_{t}^{\lambda}\left\{V_{t+1}\left(W_{t+1}\right)\right\}\right) \mathbb{E}_{t}^{\lambda}\left\{C_{t+1}^{*-\gamma}\left(1+R^{f}+w_{t}^{*}\left(R_{t+1}-R^{f}\right)\right\}\right\} .\right.
\end{aligned}
$$

The timing is as follows, first the agent consumes and afterwards the investment is made, so because I solve this problem via backward recursion I already found the optimal asset weights at time $t$, hence I have $R_{t+1}^{P *}$. I proceed as before, first I calculate the inner conditional expectations, if necessary plug them into the appropriate functions, take the weighted averages to get the K-dimension out, and finally plug parts of the calculations into other functions. The optimal consumption strategy then follows analytically.

Note however that the conditional expectation $\mathbb{E}_{t}^{\lambda}\left\{C_{t+1}^{*-\gamma}\left(1+R^{f}+w_{t}^{*}\left(R_{t+1}-R^{f}\right)\right)\right\}$ needs to be strictly positive, otherwise the optimal consumption will be negative. Hence following Koijen, Nijman, and Werker (2010) I approximate the logarithm of this conditional expectation:

$$
\begin{array}{r}
\mathbb{E}_{t}^{\lambda}\left\{C_{t+1}^{*-\gamma}\left(1+R^{f}+w_{t}^{*}\left(R_{t+1}-R^{f}\right)\right)\right\} \simeq \\
\exp \left(\rho_{0}+\rho^{\prime} f\left(Y_{t}, \lambda_{t}^{B}\right)\right)
\end{array}
$$

After all these steps I obtain the optimal consumption and investment decisions at all $(\mathrm{N} \mathrm{x}$ M) grid points at each point in time. Finally I start from the initial states and simulate forward. Depending on the realized wealth levels at each time period (the endogenous state variable), I use the corresponding optimal investment and consumption strategies. This results in the optimal policies for every simulation path. 


\section{A.6 Short summary life-cycle problem with maximin preferences}

Investors preferences are described by maximin expected utility, which in effect means that the agent maximizes his utility with respect to the worst case belief. The agent is uncertain about the equity risk premium. I solve the following Bellman equation:

$$
\begin{aligned}
V_{t} & =\max _{w_{t}, C_{t}} \min _{\lambda \in \Lambda_{t}}\left[u\left(C_{t}\right)+\beta p_{t+1} E_{t}^{\lambda}\left\{V_{t+1}\left(W_{t+1}\right)\right\}\right], \text { with } \\
u\left(C_{t}\right) & =\frac{C_{t}^{1-\gamma}}{1-\gamma} .
\end{aligned}
$$

As described above I restrict the domain of beliefs about the equity risk premium to lie between $\left[\lambda_{t}^{B}-2 \sigma_{t}^{B}, \lambda_{t}^{B}+2 \sigma_{t}^{B}\right]$. This is necessary to put a bound on the worst case belief, which would else be minus infinity since the beliefs are normally distributed.

\section{A.7 The first order conditions - maximin preferences}

In each period I find the optimal asset weights by setting the first order condition equal to zero

$$
E_{t}^{\lambda_{t}^{m i n}}\left(C_{t+1}^{*-\gamma}\left(R_{t+1}-R^{f}\right)\right)=0
$$

where $\lambda_{t}^{\min }$ is the lowest equity premium in $\Lambda_{t}$. $C_{t+1}^{*}$ denotes the optimal real consumption level. The optimal consumption follows from

$$
C_{t}^{*-\gamma}=\beta p_{t+1} E_{t}^{\lambda_{t}^{m i n}}\left(C_{t+1}^{*-\gamma} R_{t+1}^{P *}\right)
$$

\section{A.8 Optimization procedure for the optimal asset weights and consumption - maximin preferences}

As described in Section A.4 and A.5, I calculate the realization of the Euler condition and regress these on a polynomial expansion in the state variables to obtain an approximation of the conditional expectation of the Euler condition

$$
\lambda_{t}^{\min }\left(C_{t+1}^{*-\gamma}\left(R_{t+1}-R^{f}\right)\right) \simeq \rho^{\prime} f\left(Y_{t}, \lambda_{t}^{B}\right)
$$

In addition I employ a further extension, introduced in Koijen, Nijman, and Werker (2010). They found that the regression coefficients $\rho$ are smooth functions of the asset weights and, consequently, I approximate the regression coefficients $\rho$ by projecting them further on polynomial expansion in 
the asset weights:

$$
\rho(x) \simeq \Psi g(x) .
$$

The Euler condition must be set to zero to find the optimal asset weights:

$$
f\left(Y_{t}, \lambda_{t}^{B}\right) \Psi g(w)^{\prime}=0
$$

Similarly, I approximate the Euler condition for optimal consumption via regressing the realization of the Euler conditions on a polynomial expansion in the state variables.

\section{B Survey of Consumer Finances and allocation to stocks}

The Survey of Consumer Finances is a triennial survey on the financial assets of the household. It provides information on assets on the balance sheet, pensions, income, and demographics of the household. Participation in the survey in strictly voluntary and about 4500 families are interviewed. It is a repeated cross-section and only the years 1983 to 1989 are partly a panel study. The median length of an interview is about 75 minutes, but an interview with a family with complex finances can take up to several hours. High income households are over-sampled to measure asset holdings more accurately, since wealth in the US is highly concentrated among a relatively small number of households. About two thirds of the sample, 3000 households, is drawn from a national area probability sample which represents the entire population. The remaining one third, 1500 households, is drawn from tax records to get the list of high income households. Weights are used to account for both nonresponse and the difference between the initial sample design and to the actual distribution of population characteristics. In the case of missing data, multiple imputation is used to solve this problem.

Financial wealth (FIN) is the sum of liquid assets (checking, savings, money market, and call accounts), certificates of deposit, directly held mutual funds, stocks, bonds, quasi-liquid retirement accounts which consists of IRAs/Keoghs, thrift accounts, and future pensions, savings bonds, cash value of whole life insurance, other managed assets (trusts, annuities, and managed investment accounts), and other financial assets (loans from the household to someone else, future proceeds, royalties, futures, non-public stock, deferred compensation, oil/gas/mineral investment). The part of financial assets invested in stocks (EQUITY) consists of directly held stock, stock mutual funds, and retirement assets invested in stocks. I follow the Survey of Consumer Finances in calculating this. The stock investment includes the entire directly held stock, entire stock mutual funds, half of the value of the combination mutual funds, and the fraction of the value of IRAs/Keoghs that is invested in stocks. Similarly the fraction of the value of other managed assets invested in stocks is added and the part of the value of the thrift account that is allocated to stocks. 
The fraction of agents participating in the stock market is determined by calculating which weighted fraction in the total sample has a stock investment larger than zero. Furthermore the conditional allocation to equity is the fraction allocated to stocks, conditional on participation in the stock market. Note that I use weights to calculate the participation rate and the conditional allocation to stocks to adjust for nonresponse and the non-equal probability design of the survey. 